\title{
IIII
}

CROATIAN NATIONAL BANK

Working Papers W-46

\section{Exchange Rate Pass-Through in the Euro Area}

Mariarosaria Comunale and Davor Kunovac 



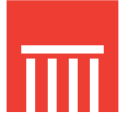

HNB

WORKING PAPERS W-46 


\section{PUBLISHER}

Croatian National Bank

Publishing Department

Trg hrvatskih velikana 3, 10002 Zagreb

Phone: +38514564555

Contact phone: +38514565006

Fax: +38514564687

\section{WEBSITE}

www.hnb.hr

EDITOR-IN-CHIEF

Ljubinko Jankov

\section{EDITORIAL BOARD}

Vedran Šošić

Gordi Sušić

Davor Kunovac

Tomislav Ridzak

Evan Kraft

Maroje Lang

\section{EDITOR}

Romana Sinkovic

The views expressed in this paper are not necessarily the views of the Croatian National Bank. Those using data from this publication are requested to cite the source.

Any additional corrections that might be required will be made in the website version.

ISSN 1334-0131 (online) 


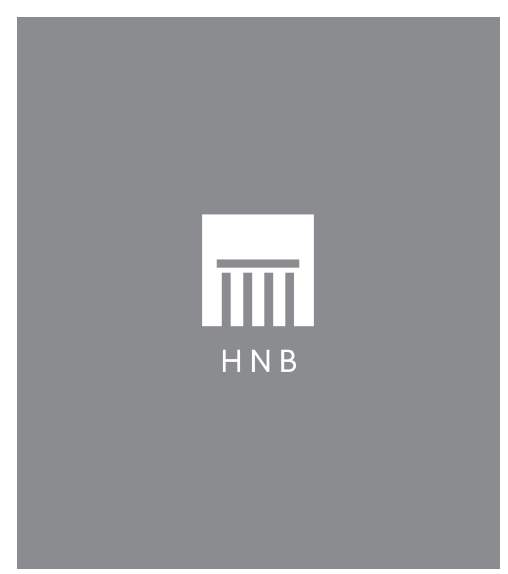

CROATIAN NATIONAL BANK

WORKING PAPERS W-46

Exchange Rate Pass-Through in the Euro Area

Mariarosaria Comunale and Davor Kunovac Zagreb, January 2017 



\title{
Exchange Rate Pass-Through in the Euro Area*
}

\author{
Mariarosaria Comunale \\ Davor Kunovac \\ Bank of Lithuania ${ }^{\dagger}$ \\ Croatian National Bank $\ddagger$
}

This version: September 2016

\begin{abstract}
In this paper we analyse the exchange rate pass-through (ERPT) in the euro area as a whole and for four euro area members - Germany, France, Italy and Spain. For that purpose we use Bayesian VARs with identification based on a combination of zero and sign restrictions. Our results emphasize that pass-through in the euro area is not constant over time - it may depend on a composition of economic shocks governing the exchange rate. Regarding the relative importance of individual shocks, it seems that pass-through is the strongest when the exchange rate movement is triggered by (relative) monetary policy shocks and the exchange rate shocks. Our shock-dependent measure of ERPT points to a large but volatile pass-through to import prices and overall very small pass-through to consumer inflation in the euro area.
\end{abstract}

Keywords: Exchange rate pass-through, import prices, consumer prices, inflation, bayesian vector autoregression.

JEL Codes: E31, F3, F41.

${ }^{*}$ This paper is based on our work for the Low Inflation Task Force of the ECB and the Eurosystem within the Working Group on Econometric Modelling. We would like to thank Chiara Osbat, Fabio Canova, the members of the task force and working group and an anonymous referee for their comments. Excellent research assistance was provided by Karlo Kotarac. The conclusions expressed in the paper are those of the authors and do not necessarily represent the official views of the Bank of Lithuania, the Croatian National Bank or the European Central Bank. This paper is also available at the ECB Working Paper Series: www.ecb.europa.eu/pub/pdf/scpwps/ecbwp2003.en.pdf and the Bank of Lithuania Working Paper Series: www.lb.lt/working_paper_series_2016_no_38.

${ }^{\dagger}$ Totoriu g. 4, LT-01121, Vilnius, Lithüania. E-mail: mcomunale@lb.lt ; mariarosaria.comunale@gmail.com

${ }^{\ddagger}$ Trg hrvatskih velikana 3, Zagreb 10002, Croatia. E-mail: davor.kunovac@hnb.hr 


\section{Non-technical summary}

The relationship between exchange rates and inflation, i.e. the exchange rate pass-through (ERPT), is of particular importance for monetary policy makers. It is of a special interest in a period of low inflation, given that both the size of this pass-through and its speed of transmission are essential for a proper assessment and management of the monetary policy and to improve inflation forecasting (Hahn, 2003; Forbes, 2015).

In this paper we provide some fresh evidence on exchange rate pass-through on inflation in the euro area using structural Bayesian VARs. We conduct the analysis for the aggregate euro area (EA) and also for four euro area members - Germany, France, Italy and Spain. The data are quarterly covering the period 1992Q1-2016Q2 (max). With the ECB policy rate constrained by the zero lower bound (ZLB) over a significant portion of the sample under investigation, we use shadow interest rates of Wu and Xia (2016) to represent both conventional and unconventional monetary policy actions.

In the first part of our paper we identify a single exchange rate shock and study how it affects inflation in the euro area. The results of this exercise suggest that the exchange rate pass-through in the euro area declines along the pricing chain. This result is well documented in the related literature (e.g. Hahn, 2003; McCarthy, 2007). The common explanations of the phenomenon include large transportation, wholesaling and retailing costs that come at later stage of the distribution chain. Also, price indexes at later stage include a smaller portion of tradable goods compared to the import prices and therefore automatically their reaction to an exchange rate shock is weaker. Estimates of the pass-through for the euro area are corroborated by the results at the country level. However, for the ERPT to import prices, Spain and Italy have larger pass-through coefficients compared to Germany and France. This outcome may signal a different pattern of imports of tradable goods and services, i.e. from countries which price their products in other currencies (mainly USD-related).

In the second part of our paper we try to account for a possible shock-dependence of the exchange rate pass-through. Our results emphasize that pass-through in the euro area is not constant over time - it may depend on a composition of economic shocks governing the exchange rate. Our results suggest that regarding a relative importance of individual shocks, it seems that pass-through is the strongest when exchange rate movement is triggered by (relative) monetary policy and the exchange rate shocks, both in case of import and consumer price inflation. We also argue that an exchange rate appreciation following a demand shock may increase domestic prices. In other words, an increase in prices after a demand shock may offset a standard negative impact of exchange rate appreciation to prices. Lastly, 
ERPT ratios for import prices are larger in Italy and Spain than in the other considered members or the whole euro area, confirming some previous results. Overall, our shock-dependent ERPT measure suggests that the ERPT to import prices in the euro area has been weak during the very recent period and close to zero to consumer prices.

The main finding of our paper is that exchange rate pass-through in the euro area may be more difficult to measure than usually considered. Our results highlight that historical estimates of the exchange rate pass-through may be of limited help when predicting pass-through effects in the future without making some strong assumptions on the composition of shocks underlying the nominal exchange rate. 


\section{Introduction}

The relationship between exchange rates and inflation, i.e. the exchange rate pass-through, is of particular importance for monetary policy. It has been well recognised that both the size of this pass-through and its speed of transmission are essential for a proper assessment of monetary policy and to improve inflation forecasting (Hahn, 2003; Forbes, 2015). Exchange rate pass-through is also of special interest to monetary policy maker in a period of low inflation. One of the channels of non-conventional monetary policy is indeed the exchange rate but the transmission of the exchange rate channel is still not well understood. In this paper, we therefore provide some fresh evidence on Exchange Rate Pass-Through (ERPT) in the euro area using structural Bayesian VARs. We conduct the analysis for the aggregate euro area (EA) and also for four main euro area members - Germany, France, Italy and Spain, looking at the main differences across countries.

Within a multivariate framework, ERPT is typically estimated using the Cholesky identification scheme (see for example Hahn, 2003; McCarthy, 2007; and Ca' Zorzi, 2007). This approach however has the important disadvantage of imposing some strong contemporaneous restrictions. In addition, the estimated ERPT may be affected by the ordering of variables when the Cholesky factorisation is used to identify structural shocks. To cope with this problem, in the paper we first isolate an exogenous movement in exchange rate (somewhat loosely labelled as the exchange rate shock) according to a set of sign restrictions imposed on the impulse response function and study how it affects import and consumer inflation in the euro area. ${ }^{1}$ In line with related theoretical literature, ERPT in the euro area calculated in this way is not complete and declines along the pricing chain. These results hold true both for the aggregate euro area economy and at a country level. Overall, our results indicate that an exogenous shift in the exchange rate results in reasonable estimates of the pass-through coefficients - both in their magnitude and dynamics over time and along the pricing chain. However, these exogenous movements may explain only a small portion of the overall variability in nominal exchange rates and, consequently, their importance for inflation dynamics is rather limited. It seems that other economic shocks account for the majority of variation in the exchange rate, suggesting that estimates of the ERPT conditional on exchange rate shocks only may be insufficient for a comprehensive assessment of how changes in exchange rate affect inflation. In order to get a full picture of ERPT mechanism in the euro area it thus

\footnotetext{
${ }^{1}$ Exogenous shifts in exchange rate are first identified with sign restrictions by An (2006) for a number of industrial countries. Jovičić and Kunovac (2015) applied a similar methodology to Croatia, adding block exogeneity assumption to a specification in order to account for properties of a small country.
} 
is necessary to look at how exchange rate movements pass through to inflation when they are triggered by various economic shocks, other than by exogenous shifts in exchange rate itself. The strong assumption that the exchange rate is governed by exogenous shocks to itself has already been challenged in related literature by Shaumbaugh (2008) and Forbes et al. (2015). Price setters may react differently to exchange rate movements triggered by different economic shocks. Another example, when the exchange rate is predominantly determined by demand shocks that presumably appreciate the exchange rate, exchange rate pass-through estimates may be of the "wrong" sign. Demand shocks may appreciate the exchange rate but also raise inflation and the sign of the correlation between exchange rates and prices will be in contrast to the expected one. These simple arguments suggest that ERPT may really depend on the shock that triggers the exchange rate movements - a feature often overlooked in empirical analyses of exchange rate pass-through.

In the second part of our paper we try to account for a possible shock dependence of the exchange rate pass-through in the euro area. To do so we expand our specification and take into account six possible underlying shocks that may cause exchange rate movements in the first place. In contrast to a simple one-shock framework, having more shocks in the model complicates the assessment of pass-through to prices - it may now depend on what triggers the exchange rate movement. To account for that, for each shock the pass-through is computed as the ratio between the cumulated impulse response functions of inflation and exchange rates (similar to Shaumbaugh, 2008 and Forbes et al., 2015). These pass-through ratios reflect the correlation between exchange rate and inflation conditional on each of the identified shocks and therefore may serve as a shock dependent pass-through measure. Besides calculating the pass-through ratios, in order to assess the relative importance of individual shocks for exchange rate dynamics we also look at the historical decomposition of the euro nominal effective exchange rate in the period of interest. Given the estimated shock dependent pass-through ratios and exchange rate historical decomposition, we build a time-varying measure of pass-through to HICP and import prices. Naturally, different compositions of economic shocks hitting the exchange rate will result with different ERPT estimates. This way of looking at exchange rate pass-through can offer an additional explanation for the variation in pass-through coefficients: the observed variation in exchange rate pass-through may just reflect a different composition of economic shocks affecting countries over time.

In order to calculate the shock dependent ERPT measure we identify a full set of six economic shocks: euro area supply shock; euro area demand shock; global supply shock; global demand shock; an exogenous exchange rate shock and a relative monetary policy shock. The set of shocks includes a relative 
monetary policy shock for the euro area with respect to the US also accounting for both conventional and non-conventional policy measures. ${ }^{2}$ Unconventional policies are accounted for by using shadow rates from $\mathrm{Wu}$ and Xia (2016). We use a relative measure of monetary policy, because otherwise we may exclude an important factor for the exchange rate, i.e. the effect coming from the other side of the rate (Glick and Leduc, 2015). As a robustness check we also estimate a specification with standard, non relative measure of monetary policy in order to examine potential differences in ERPT estimates when different measures of monetary policy are used.

Our shock-dependent measure of ERPT points to a large but volatile pass-through to import prices in the euro area. Pass-through to consumer inflation on the other hand is overall very small. Regarding a relative importance of individual shocks, it seems that pass-through is the strongest when exchange rate movement is triggered by relative monetary policy shocks and its own exchange rate shocks. It holds true for both euro area economy as a whole as well at a country level. However, our results should be interpreted with some caution because there may be a large model uncertainty present when modelling determinants of exchange rate. To clarify, in our baseline specification, the pass-through was proved to be important when exchange rate movement was triggered by two shocks - monetary policy shock and exchange rate shock. However, this was not surprising because we explicitly imposed the signs onto responses of the euro nominal effective exchange rate to these two particular shocks. In order to test how our results depend on these restrictions we specify an alternative VAR and relax the restriction on how monetary policy shock influences exchange rate. In that case, exchange rate pass-through following a monetary policy shock was not significant at all, suggesting that our results heavily depend on the identification pattern imposed onto impulse responses. This is in line with the exchange rate disconnect puzzle introduced by Meese and Rogoff $(1983)^{3}$ and then analysed by Obstfeld and Rogoff (2000) among others, which stress that nominal exchange rates seem to be disconnected from macroeconomic fundamentals especially in the short run. ${ }^{4} 5$

\footnotetext{
${ }^{2}$ The link between unconventional monetary policy and exchange rates has been studied in the literature. For instance the non-standard measures as an exogenous rise in the ECB's balance sheet, seems to make the nominal effective exchange rate depreciate (Boeckx et al., 2014). Indeed a joint tool of conventional and unconventional monetary policy variables may help to better control output and inflation dynamics, as stressed in Bluwstein and Canova (2016). Peersman (2012) also finds that the response of inflation to conventional monetary policy shocks seems to be insignificant, while the results in case of an exogenous increase in central bank balance sheets at the zero lower bound leads to a temporary rise in economic activity and consumer prices.

${ }^{3}$ Meese and Rogoff (1983) and subsequent studies find that the economic fundamentals they consider (such as output, stock of money, stock of bonds, and differences in short-term interest rates) cannot explain actual exchange rate movements.

${ }^{4}$ There is some forecasting power at horizons of two to four years but attempts to forecast at more policy-relevant horizons of one month to one year have been far less successful (Rogoff and Stavrakeva, 2008).

${ }^{5}$ Recently however, Horioka and Ford (2016) claim that the puzzle may be caused by not using the right fundamentals and because the contributions to this strand did not allow for the forward-looking nature of exchange rate determination.
} 


\section{Exchange rate pass-through in the literature}

Looking at the main contributions from the literature so far, the ERPT has been computed by using different approaches, as surveyed in Saiki (2011) and Comunale (2015a). The main findings from the empirical literature on ERPT evidence a decline both at the import price level and down the pricing chain in major advanced economies. At the import price stage, reasons why pass-through may have declined relate to an increased role for hedging, either naturally by increasing global value chain integration or via cheaper financial instruments. The decline in the ERPT to import prices may also be related to a sectoral shift in the composition of imports from sectors with high ERPT, such as energy, to sectors with lower ERPT, such as manufacturing and food (Campa and Goldberg, 2005; Osbat and Wagner, 2006; Di Mauro et al., 2008). Other possible explanations are related to the increase in invoicing in euro (ECB 2014), the improvement in monetary policy and substantial changes in other macroeconomic conditions (as inflation, per capita incomes, tariffs, wages, long-term inflation, and long-term exchange rate variability), together with globalization and increasing competition (Taylor, 2000). At the level of HICP, ERPT gets further dampened by the increasing share of distribution costs in the final cost of retail sales and also by the mechanism highlighted by Taylor (2000).

From a theoretical point of view, the analysis of ERPT is mainly based on Pricing To Market (PTM) studies, developed by Krugman (1987), Knetter (1989), Marston (1990) and Goldberg and Knetter (1997), in which the exchange rate induces price discrimination in international markets with a variation in the various mark-ups. The PTM depends on the export demand function; therefore an increase in the demand elasticity caused by a variation of import or consumer prices gives a lower mark-up in this market. The marginal costs vary due to variations in output. We can have complete ERPT (the elasticity is equal to one) only if the mark-up and the marginal costs are constant. Incomplete ERPT is hence defined as elasticity of prices lower than one. The New Open-Economy Macroeconomic (NOEM) literature approached ERPT introducing it into a dynamic general-equilibrium (DGE), openeconomy model with well-specified micro-foundations stressing how pass-through could be incomplete in an environment characterized by imperfect competition and pricing to market (PTM). Corsetti et al. (2005) explain that ERPT falls with firms' monopoly power and the size of mark-ups and even if prices and wages are fully flexible (i.e. there are not nominal rigidities) ERPT can be incomplete. Empirically, in an OECD context ERPT has declined in recent years. More recently Corsetti et al. (2009) propose a theoretical contribution which stresses that ERPT changes depending on whether shocks hit upstream 
or downstream producers, and hence different shocks to the exchange rate could generate different effects on the economy ${ }^{6}$.

When ERPT is estimated by a VAR, our adopted framework in this paper, the exchange rate shock is often identified by the Cholesky factorisation (Hahn, 2003; McCarthy, 2007; and Ca' Zorzi, 2007). In order to circumvent the problems related to the Cholesky identification, An (2006) identifies an exogenous shift in exchange rates consistent with a number of sign restrictions imposed on the impulse response function. However, this approach fails to account for variations in exchange rates triggered by other economic shocks. So, the second, more economically meaningful approach, analogous to what is standard in looking at the impact of oil prices on inflation, asks the question of what moves exchange rates and consumer prices in the first place. Depending on the shock, the response of consumer prices and of exchange rates will be different. Recently, a deeper analysis of what causes exchange rates to move is provided in Farrant and Peersman (2006). The authors find a notable important role for nominal shocks in explaining exchange rate fluctuations, which is confirmed making a distinction between monetary policy shocks and pure exchange rate shocks, still finding an important role for the latter. In addition, they emphasize the substantial contemporaneous effect of both monetary policy and pure exchange rate shocks. The idea that ERPTs may depend on the composition of shocks governing the exchange rate was pioneered by Shambaugh $(2008)^{7}$ and was also recently made forcefully in a speech by Bank of England's MPC member K. Forbes. ${ }^{8}$ A similar approach also based on a BVAR with zero and sign restrictions but with an alternative identification scheme is in Jarocinski and Bobeica (2016). ${ }^{9}$

\subsection{Contribution of this paper}

Our paper builds on the literature and estimates exchange rate pass-through imposing sign and zero restrictions for the main euro area countries and the aggregate euro area economy. We first identify a single exchange rate shock consistent with a number of non controversial sign restrictions and study how this shock affects inflation along the pricing chain in the euro area. After that we specify a full set of six structural shocks, including an exchange rate shock, and look at how ERPT varies when exchange

\footnotetext{
${ }^{6}$ Here the tradable goods and the local inputs are poor substitutes in production. Hence the presence of local inputs tends to mute the response of upstream prices to shocks and makes the ERPT incomplete, even in the absence of nominal rigidities.

${ }^{7}$ His results indicate that the ERPT depends on whether the shocks are more related to supply, relative demand, nominal factors, or foreign price movements.

${ }^{8}$ See also Forbes et al. (2015). The authors analyse the ERPT for the United Kingdom, finding that this is relatively large in response to domestic monetary policy shocks, but smaller in response to domestic demand shocks.

${ }^{9}$ They apply the identifications by Corsetti et al. (2014) to distinguish global shocks from domestic ones and Baumeister and Benati (2013) to identify conventional and unconventional monetary policy.
} 
rate is driven by different shocks. Having estimated similar ERPT coefficients when exchange rate shock is identified within different specifications - first as a single shock and then together with a number of other structural shocks - points to the single shock framework as a sufficient to isolate an exchange rate shock from other shocks in the model. However, in order to estimate the exchange rate pass-through conditional on other structural shocks one needs to identify a full set of structural shocks in a VAR.

In a model with a full set of structural shocks, our identification is similar to that in Forbes et al. (2015) but there are some important distinctions between the two papers regarding the methodology and the identification scheme used to identify structural shocks. Although both papers impose zero and sign restrictions on the impulse response function, we use a slightly different methodological framework for that purpose - Forbes et al. (2015) rely on Binning (2013) while we use the algorithm proposed by Arias et al. (2014). Arias et al. (2014) provide a rigorous proof of validity of their algorithm from the Bayesian perspective. They show that their algorithm really draws from the posterior distribution of structural parameters conditional on the sign and zero restrictions which is the property that other strategies of imposing these restrictions fail to provide. Moreover, the identification in Forbes et al. (2015) suits a small open economy, while in our case we also have the aggregate euro area, which may have a more relevant impact on the world economy. For that reason we tested several strategies of how to identify both domestic and foreign shocks. At the country level in the euro area, we implemented strong block exogeneity assumption while at an aggregate level we relaxed that assumption and tested alternative specifications.

Finally, we contribute to the related literature on pass-through by constructing an explicit timevarying measure of ERPT in the euro area, where the time variation comes from the different composition of identified shocks hitting the euro area over time.

\section{Data description}

We use quarterly data from 1992Q1-2016Q2 (max) for the euro area as a whole (19 countries) and four member states - Germany, France, Italy and Spain. ${ }^{10}$ The data are in log first differences except the interest rates.

\footnotetext{
${ }^{10}$ The time span available for the data depends on the country and the variables. In case of the euro area as a whole, the data start from 1992Q1 for GDP, HICP and interest rates; while the NEER data start from 1994Q2, import prices from 1995Q3 and foreign export prices from 1994Q3. For Germany and France, also import prices start from 1992Q1 and foreign prices from 1993Q2. For Spain the data for the GDP start in 1995Q2; NEER in 1994Q3; import prices 1995Q2 and foreign export prices in 1993Q2. Concerning Italy, the data for the GDP start in 1995Q2; NEER in 1994Q2; import prices 1996Q2 and foreign export prices in 1993Q2.
} 
Concerning the data sources, EONIA short-term rates are from the ECB Statistical Data Warehouse (SDW). ${ }^{11}$ The foreign export prices are a trade-weighted average of partners' exports price indices, seasonally adjusted. The pertaining weights are from the Directorate-General for Economic and Financial Affairs (DG ECFIN), Price and Cost Competitiveness database and the export price indices are from OECD and Eurostat. In the specification with the EUR/USD, we used US export prices from the Bureau of Labor Statistics. The NEER is here the Nominal Effective Exchange Rate vis-á-vis 42 partners and the data are from ECB SDW. ${ }^{12}$ The bilateral Exchange rate EUR/USD is the ECB reference nominal exchange rate, US dollar/Euro, 2:15 pm (C.E.T.), from the ECB SDW. The GDP series are taken as gross domestic product at market prices for the total economy, calendar and seasonally adjusted. The HICP is the Harmonised Index of Consumer Prices, seasonally adjusted. The series for GDP and HICP are from Eurostat. The import prices index is the deflator for imports of goods and services, $2010=100$, seasonally adjusted and adjusted by working days. Also import prices are from the ECB SDW.

In order to identify a relative monetary policy shock, which includes both conventional and unconventional policy actions, we used the difference between the euro area and the the US shadow interest rates calculated by $\mathrm{Wu}$ and Xia (2016). ${ }^{13}$ The proposal of having a shadow rate has intuitive appeal because when it is positive it equals the actual short-term rate, but the shadow rate is free to evolve to negative levels after the actual short-term rate becomes constrained by the Zero Lower Bound (ZLB). As such, the shadow rate indicates how the short-term rate would have behaved if policymakers could have driven it negative. This rate has some advantages with respect to other methods to design a measure of monetary policy stance, mainly it's easier to understand than a synthetic indicator from principal component/factor analyses and can be directly comparable with the short-term interest rate in normal times (Lombardi and Zhu, 2014). ${ }^{14}$

\footnotetext{
${ }^{11}$ The short term interest rates for the euro area (changing composition) are the EONIA rates, historical close, average of observations through period.

${ }^{12}$ The data are downloaded from ECB SDW but are originally from Economic Outlook OECD June 2016, for the 4 countries, while for EA are from ECB. The NEER for the 4 countries includes the intra-EA trade, while for the EA is not, leaving only extra-EA partners.

${ }^{13} \mathrm{We}$ use the rates computed by $\mathrm{Wu}$ and Xia (2016), constructed as a comprehensive measure of shadow rates. The authors propose a simple analytical representation for bond prices in a multifactor shadow rate term structure model that can be applied directly to discrete-time data. The authors also demonstrate that this model offers an excellent empirical description of the recent behaviour of interest rates, as compared to the benchmark Gaussian affine term structure model (GATSM) previously applied in this strand of literature (see Diebold and Rudebusch (2013) among others). Here the short rate and all other model-implied interest rates cannot go below a minimum rate set as 25 basis points (instead of zero as in Bauer and Rudebusch, 2015).

${ }^{14}$ As pointed out by Krippner (2014), there are some drawbacks when we have negative shadow rates, because these are not an actual interest rate faced by economic agents and may vary with the practical choices underlying their calculations and especially they depend to: the specification of the shadow/ZLB model and the data and method used for estimation. Using shadow rates for that purpose has been questioned also by Francis, Jackson and Owyang (2014) who find that when using a dataset that spans the pre ZLB period throughout the ZLB period the shadow rate may be a fairly good proxy for
} 


\section{ERPT identification from exogenous movements in exchange rates}

\subsection{Identification}

In this section we first identify an exogenous shift in the exchange rate according to a set of sign restrictions and then study how it affects inflation in the euro area. To do so we rely on a set of restrictions proposed in An (2006) and estimate a similar specification to calculate the ERPT in the euro area and then for the four member states. The sign restrictions we use are motivated by the relation between foreign export prices and domestic import prices in a two country model, in our case the two countries being the euro area and the rest of the world (An 2006 and Jovičić and Kunovac 2015):

$$
P^{m}=E R \times P^{x}
$$

where $P^{m}$ denotes import prices, $E R$ is the exchange rate expressed in domestic currency per unit of foreign currency and $P^{x}$ denotes the export prices. Taking the logarithm yields:

$$
p^{m}=e r+p^{x}=e r+\operatorname{markup} p^{x}+m c^{x} .
$$

The expression above reflects the fact that exporter prices are essentially a mark-up over marginal costs. While the related literature includes import prices in a VAR when estimating the ERPT, export prices are generally ignored. However, exchange rates also influence export prices by affecting the mark-up and marginal costs. For example, in the presence of short-run price rigidities exporting firms' markup will fall with currency appreciation (Kim, 1990). Similarly, marginal costs will probably also fall due to cheaper imported inputs (Devereux and Genberg, 2010). The literature usually deals with the transmission of the nominal effective exchange rate to inflation at various stages of the production chain. In the context of the identification based on sign restrictions, in that case the econometric specification used should consider the index of export prices that correspond to the effective exchange rate used using the same weighting pattern as that used for the NEER.

To specify the set of sign restrictions we rely on throughout this analysis let us first note that the equation above naturally suggests how euro area import prices and the world export prices react to

monetary policy by producing impulse responses similar to those based on the non-ZLB benchmark. Lombardi and Zhu (2014) and Wu and Xia (2016) in that regards, claim that the common dynamics among different shadow rates point to the same economic conclusion and also provide evidence that the shadow rates can effectively summarize relevant information at the ZLB. 
shocks to NEER. The signs of reactions then offer a possible identification strategy for the exchange rate shock with sign restrictions. Regarding implementation, our model includes seven variables - EA import inflation, EA PPI inflation and EA HICP inflation, output gap, exchange rate, world export prices and oil prices. This set of variables is sufficient to isolate exogenous shifts in exchange rate - the exchange rate shock - and estimate the ERPT to domestic prices for the euro area and its members. In order to identify the exchange rate shock we consider the following variables and impose sign restrictions on the impulse responses at impact and possibly several periods following the impact:

Output gap The identification in An (2006) assumes that the exchange rate shock (depreciation) will decrease export prices and increase EA import prices. Thus the effect of the exchange rate shock to the output gap in euro area may be positive in this baseline specification. However, this restriction proved to be unnecessary to identify the exchange rate shock and is therefore left out from most of the tested specifications. The reaction of the output gap to exchange rate shock is thus left unrestricted.

Exchange rate The exchange rate, here represented by the NEER, is expressed in domestic currency per unit of foreign currency and will naturally increase following the exchange rate shock.

Euro area prices Import, PPI and HICP price inflation series will all increase following the exchange rate depreciation.

Foreign prices Foreign prices will decrease following the exchange rate shock.

Oil prices The impact of the exchange rate shock to oil prices is left unrestricted. Oil prices should account for supply shock in the model.

Short term interest rate A monetary policy whose objective is price stability may occasionally want to react to exchange rate movements so An (2006) controls for that in his specification and includes the short-term interest rate (EONIA) in a VAR. However this effect proved to be minor in our case and therefore we omit the interest rate from our final specification in order to reduce the dimension of the model. 
Table 1: Identification pattern based on zero and sign restrictions

\begin{tabular}{lcccccc}
\hline Variables & Output Gap & NEER & EA Prices & Foreign prices & Oil prices & ST interest rates \\
NEER shock & $?$ & + & + & - & omitted \\
\hline Note: '+' denotes positive sign, '-' denotes negative, '0' denotes zero restriction and \\
'?' denotes unrestricted response & & &
\end{tabular}

\subsection{Results}

In order to identify the exchange rate shock with sign restrictions we first estimate a (first-order differenced) VAR with two lags, 7 variables - EA output gap, EA import inflation, producer inflation and consumer inflation, foreign (world) export prices, nominal effective exchange rate and oil prices. ${ }^{15}$ Reduced-form parameters are estimated by imposing the independent Normal Inverse Wishart prior, as shown in the appendix, whereas structural shocks are identified as proposed by Rubio-Ramirez et al. (2010). Sign restrictions are imposed on impulse response functions at impact and one period after impact only. The ERPT is calculated as the cumulated response of inflation to an exchange rate shock. In order to make results comparable over different samples and specifications, impulse responses are normalised and reported with respect to a one-percent exchange rate shock.

Figure 1 reports the ERPT to euro area inflation as the median together with $68 \%$ error bands of the estimated impulse responses. The reported results suggest that the exchange rate shock has a largely expected impact on the prices along the pricing chain for the euro area. Our estimates indicate that pass-through to inflation in the euro area is fast, but incomplete. Most notably, ERPT declines along the pricing chain. Following a one percent depreciation of the exchange rate, after one year, import prices in the euro area rise $0.8 \%$, producer prices rise around $0.6 \%$ and consumer prices rise less than $0.2 \%$. The result that ERPT declines along the distribution chain is well documented in related literature (e.g. Hahn, 2003; McCarthy, 2007). A common explanation of the phenomenon includes large transportation, wholesaling and retailing costs that come at later stage of the distribution chain. Campa and Goldberg (2005) report that expenditures on local distribution services are 32 to 50 percent of the total cost of goods across OECD countries. Also, price indexes at later stages include a smaller portion of tradable goods compared to import prices and therefore automatically their reaction to an exchange rate shock is weaker.

\footnotetext{
${ }^{15}$ The data are quarterly covering the period 1992Q1-2015Q2 (max), transformed as log first differences (all except the interest rates).
} 

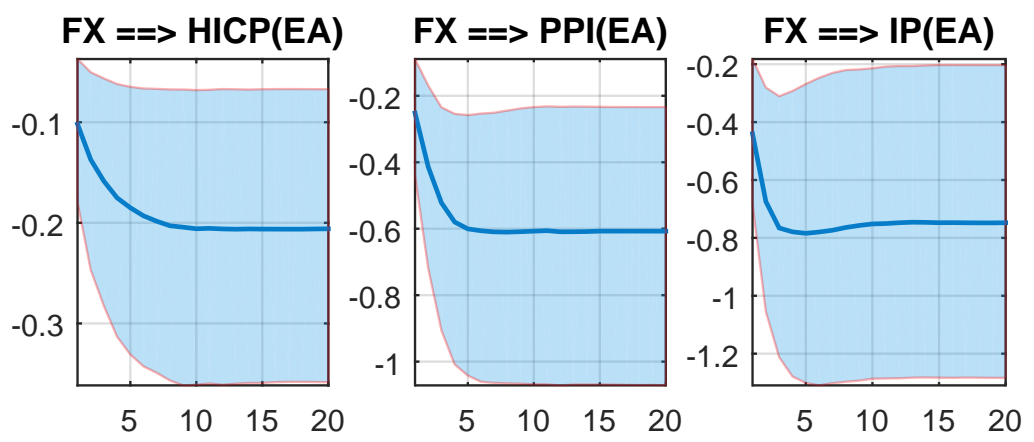

Figure 1: ERPT along the pricing chain in the euro area after a $1 \%$ exchange rate appreciation. Impulse responses to one unit shock to exchange rate, median together with $68 \%$ interval.

ERPT at country level: baseline and corrected estimates For each member state under analysis we estimated ERPT to inflation using country specific NEER indices. However this comes at a cost - the estimated ERPT estimates for individual countries are always larger in magnitude compared to those for the euro area. For that reason, based on our specification, it may be difficult to assess the importance of country-specific ERPTs for the overall inflation in the euro area. This gap between country level and aggregate estimates of the pass-through is due to the fact that the nominal effective exchange rates for individual countries, in contrast to that for the euro area as a whole, do account for the intra euro area trade. As a consequence, changes in NEER for the euro area as a whole are of a larger magnitude compared to those for individual member states and thus result with smaller ERPT estimates. In order to address that issue, and to make our estimates of ERPT for the aggregate euro area and those for individual member states mutually comparable, we report both baseline (uncorrected) and corrected ERPT estimates. Correction is based on Schröder and Hüfner (2002) and it basically adjusts the baseline estimates of ERPT for each member state so to account for extra euro area trade component in its NEER only. Effectively, for each country, our baseline estimates study how inflation changes with country-specific NEER and corrected estimates study how it changes with overall NEER for the euro area and hence provide comparable estimates of the pass-through. Baseline and corrected estimates of ERPT are the same up to a constant. Details on the procedure are given in appendix (A.2).

Estimates of the pass-through for the euro area as a whole are overall corroborated by our (corrected) results at the country level (Figure 7 , appendix). ${ }^{16}$ Despite a certain level of heterogeneity across countries under analysis the main results for the ERPTs still hold true ${ }^{17}$. ERPT is large for import prices

\footnotetext{
${ }^{16}$ For a comparison between baseline (uncorrected) and corrected ERPTs, both results are provided in Figure 7 . The magnitudes of corrected ERPTs are on the right axes. If we do not take into consideration the correction for intra-trade EA in the weights, the results may be puzzling and are not comparable with the aggregate EA. For instance the ERPT may exceed $-2 \%$, as in the case of Spain for ERPT to import prices.

${ }^{17} \mathrm{As}$ a robustness check we also ran the same exercise for EU countries not in the euro area, with USD/EUR for the
} 
and then declines down the pricing chain. The results of ERPT to consumer prices are comparable in magnitude with those for the aggregate euro area. However, for the ERPT to import prices, both Spain and Italy result with larger pass-through estimates compared to the other two considered members. This outcome may signal a different pattern of imports of tradable goods and services, i.e. from countries which price their products in other currencies (mainly USD-related). Indeed member states with a higher share of extra-EA imports invoiced in euro typically have a substantially lower degree of ERPT (ECB, $2015)^{18}$. This is reflected also in the ERPT ratios from USD/EUR to inflation, which is higher for Italy and Spain than for Germany or France. ${ }^{19}$

Speed of ERPT Looking now at the speed of pass-through, we report the results for boundary stages of the pricing chain - consumer and import inflation. ${ }^{20}$ Consistently with the literature, a shock in the exchange rate is absorbed faster by import prices than it is the case for HICP. After 1 year (4 periods in Figure 2), the import prices absorb almost 100\% of the shock, while the HICP is slower in that regards ( $85 \%$ after 1 year and $100 \%$ in 2 years period). These findings are confirmed at country level (Figure 10, appendix) with the German and French speed of ERPT being to HICP even closer to $100 \%$ after 1 year. Italy and Spain experienced a relative slower speed compared to Germany and France but in line with the results for the euro area as a whole.

\section{Overall importance of ERPT for inflation in the euro area How important has the ERPT} to prices in the euro area, based on this identifying strategy, really been during the recent period of low inflation? Our results may provide some insight into the importance that exchange rate shocks may have had during the recent episode of muted inflation rates in the euro area. For that purpose we conduct a counterfactual analysis and construct a hypothetical series of inflation in the euro area that would have been realised if identified exchange rate shocks had not occurred. Figure 3 shows import, producer and consumer inflation rates together with the counterfactual zero-exchange-rate-shock scenarios. Estimated

ERPT. For that purpose we estimate a series of monthly VARs covering the period 2000m02 - $2015 \mathrm{~m} 06$ for most of these countries, imposing the block exogeneity restrictions. Again, the pass-through is incomplete and declines along the pricing chain for all member states of the EU considered - pass-through to consumer prices is much weaker compared to that to producer prices. All the results are available upon request.

${ }^{18}$ To illustrate, for Italy, imports from Asia reached $15 \%$ of the total and energy import plays a key role compared to Germany and France (data for 2014, source ONU Comtrade). The situation is similar for Spain. In contrast, Germany imports more from EU members, including from the new member states with fixed exchange rate regimes or which use euro to price exports (this factor may be the key for imports in intermediate goods for instance).

${ }^{19}$ More details on importance of the US dollar for exchange rate pass-through are given when testing robustness of our specification. All the results are available upon request.

${ }^{20}$ The speed of ERPT for PPI is mainly located between those for IP and HICP, but with numerous exceptions in our sample. 


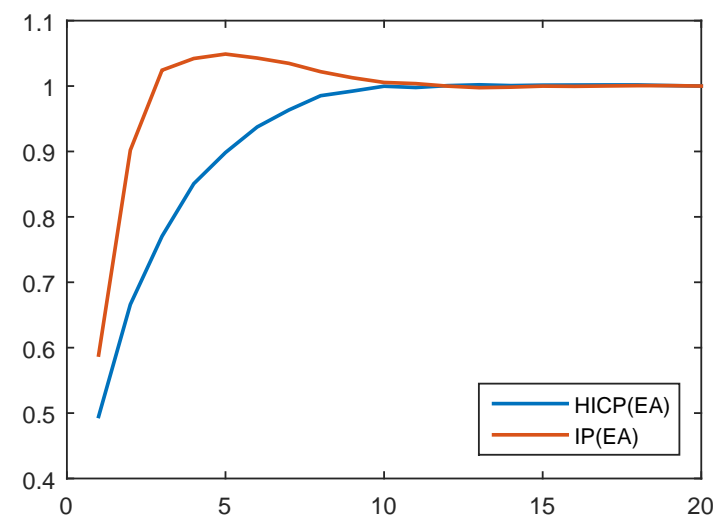

Figure 2: Speed of the pass-through for import prices and consumer prices in the euro area

counterfactuals suggest that the identified exchange rate shock has had a rather limited impact on the recent consumer prices. This counterfactual analysis has been performed also at a country level (Figure 9, appendix) and the results are very much in line with those for the aggregate euro area.

Our results indicate that an exogenous shift in exchange rates consistent with imposed sign restrictions on impulse response functions results with reasonable estimates of the pass-through coefficients. However, these exogenous movements can explain only a small portion of the overall variability in nominal exchange rates ${ }^{21}$, and consequently their importance for inflation is rather limited. In order to get a full picture of the ERPT mechanism in the euro area it may be necessary to look at how exchange rate movements pass through on inflation when they are triggered by various economic shocks, other than by identified exogenous exchange rate movements only. If other economic shocks account for majority of variation in exchange rate, the estimates of ERPT reported in this section may not be sufficient for a comprehensive assessment of pass-through in the euro area.

\subsection{Robustness check}

In order to assess the reliability and robustness of our results we perform various checks altering the variables included in our VAR, testing alternative definitions of the pass-through and imposing different patterns of sign restrictions.

\footnotetext{
${ }^{21}$ The median contribution of the identified exchange rate shock to the exchange rate forecast error variance is around $10 \%$, with $68 \%$ posterior interval being $(2 \%, 35 \%)$.
} 

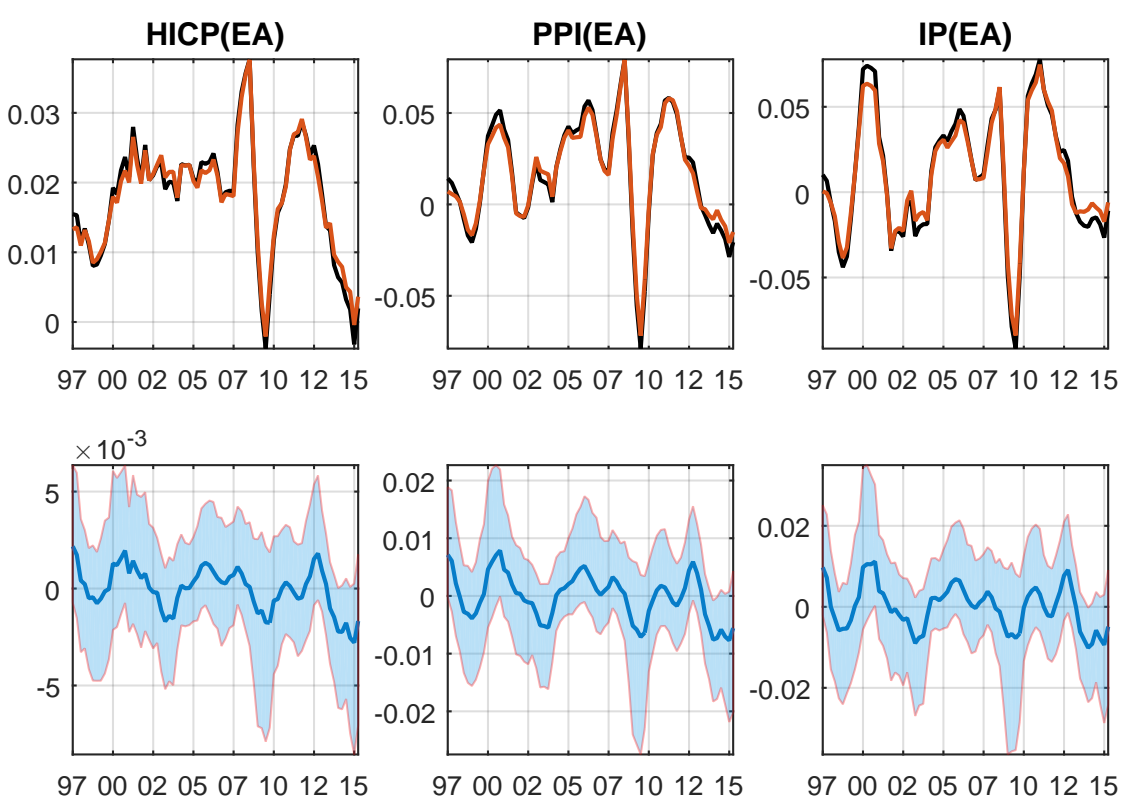

Figure 3: Inflation (in red) and counterfactual no exchange rate shock scenarios (in black). The lower panel reports the difference between the red and black lines (median together with $68 \%$ bands).

USD/EUR vs NEER First, given the importance of the US dollar for prices in the euro area ${ }^{22}$ instead of the nominal effective exchange rate and trade weighted index of foreign prices we use spot USD/EUR and US export prices and keep the sign restrictions pattern unchanged (Table 1). ${ }^{23}$ The results of this model are broadly similar to those presented in the paper - ERPT is fast but incomplete and, again, it declines along the pricing chain. In this case the ERPT to HICP is very similar to the one of NEER in magnitude, while for PPI and IP the magnitude is much smaller. This can be the indication of the importance of different import partners in the transmission and currency invoices, especially at the first step of the pricing chain. Looking at the main importers (of goods and services) for the euro area in the last years, ${ }^{24}$ non-EU trading partners count for $43 \%$ of total imports. Among them, the euro area imports $8.5 \%$ from the US, $12 \%$ from China and $7.5 \%$ from Russia. China has a less fixed

\footnotetext{
${ }^{22}$ What makes the dollar so important for inflation? Despite a growing role of the euro in international trade, the importance of the US dollar for domestic prices can be found in its special position as the most important invoicing currency in international trade. For example, many countries, especially in Asia, use the US dollars as their dominant invoicing currency. Yet, the share of the dollar as the invoicing currency is much higher compared to the actual exports to the United states (Goldberg and Tille 2009). Let us note however that the invoicing and the exchange rate pass-through need not be related - but in practice they are. Goldberg and Tille (2009) for example report that the currency of invoicing is also the currency in which prices are held steady (i.e. unadjusted following the exchange rate shock). As a result, exchange rate fluctuations pass through to import prices. Despite the low share the dollar may have in domestic imports its large fluctuation thus may have a prominent impact on domestic prices through its dominance as an invoicing (and pricing) currency in world trade.

${ }^{23}$ All the figures are available upon request.

${ }^{24}$ Data concern the period 2008-2012 (source: ECB).
} 
intermediate exchange regime vis-á-vis the USD now, hence its importance in imports may matter for the ERPT in the NEER case. Moreover, the contribution of EU members outside the euro area can play a role in explaining the differences in ERPT magnitudes. For instance imports to the euro area from the UK account for almost $10 \%$ of overall imports and Poland and Czech Republic account for $4 \%$ each. The impact of this diversified source of imports may be the key in explaining the lower ERPT to IP and PPI also in the case of USD/EUR. Lastly, we investigate the ratios by using USD/EUR exchange rate instead of NEER and the results are similar with respect to the outcomes for the NEER ERPT.

Alternative identification patterns When several inflation measures enter the specification simultaneously it is not clear whether one should restrict impulse responses corresponding to all of these measures (see An, 2006). Leaving some of the impulse responses unrestricted may be desirable in some cases because this strategy allows the data to "speak" freely. However we refrain from such an agnostic approach and impose restrictions on all of the impulse responses. In this way we ensure comparability between impulse responses in the sense that all of them are calculated based on exactly the same set of sign restrictions. To check the robustness of the employed identification strategy we relax that assumption and impulse response of that inflation measure for which pass-through is being estimated is left unrestricted. In Figure 11 and 12 (Appendix) we report these IRFs for the EA and the four countries respectively (these are not corrected for the intra-euro area trade and should be compared with the results in the left axes in Figures 7 and 8). The median results are very much in line with our baseline; we can only see a smaller pass-through in magnitude in some few specifications (i.e. for HICP and PPI in Germany and Italy). However in this case the posterior bands are somewhat wider compared to our baseline specification. Our results are now only marginally significant under $68 \%$ error bands.

ERPT ratios In order to ensure comparability across countries, impulse responses in our baseline specification are normalized so that reaction of exchange rate at impact to its own shock is equal to one. For comparison purposes, similar to An (2006) and Wolden Bache (2006) we also look at pass-through ratios: change in prices divided by the change in exchange rate, following the identified exchange rate shock (Figures 6 and 8, appendix). Looking at pass through ratios, the estimates for consumer prices are comparable in magnitude those for the aggregate euro area. Once again the main differences can be spotted for ERPT to import prices. For Spain and Italy the pass through is larger than in France or Germany. 
NEER vs REER In our last robustness check, we use the Real Effective Exchange Rate (REER) instead of the $\mathrm{NEER}^{25}$. In this way we have now a measure of price competitiveness, calculated by the NEER and relative consumer prices with respect to the partners' consumer prices. This variable may help us to checking if we properly captured the real components and then if we correctly pinned down global demand shocks. ${ }^{26}$ The results are very much in line with our outcomes by using the NEER for both euro area and the four considered members. ${ }^{27}$

\section{Shock - dependent exchange rate pass-through}

In the previous section, exchange rate pass-through is estimated conditionally on the exchange rate shock only. If other economic shocks account for the majority of variation in the exchange rate, resulting estimates of ERPT may not be sufficient for a proper assessment of exchange rate pass-through. In order to investigate how ERPT depends on the composition of economic shocks hitting the euro area, here we identify a full set of economic shocks from a six-variables BVAR. For each of the six shocks the pass-through is computed as the ratio between the cumulated impulse response function of inflation and of the exchange rate following that particular shock. This measure reflects the correlation between the exchange rate and inflation conditional on each of the identified shocks serving as a shock-dependent ERPT measure. After that, in order to assess the relative importance of individual shocks for exchange rate dynamics we look at historical decomposition of the euro nominal effective exchange rate on the period of interest. Naturally, a different composition of economic shocks governing the exchange rate dynamics will result in different estimates of exchange rate pass-through.

\subsection{Identification with zero and sign restrictions}

We identify a full set of shocks by imposing a combination of zero restrictions and sign restrictions (see appendix). Our VAR includes two lags of the following six variables - euro area real GDP, euro area HICP, euro area import deflator, world export prices and relative interest rate. ${ }^{28}$ The full set of identified economic shocks includes: euro area aggregate supply shock; euro area aggregate demand

\footnotetext{
${ }^{25}$ The data for the REERs are from Eurostat and DG ECFIN Price and Cost Competitiveness database. They are calculated as the NEER vis-á-vis 42 partner countries multiplied by domestic HICP over partners' HICP.

${ }^{26}$ REER can affect domestic GDP via exports, at least in the short-run (see Comunale and Hessel, 2014). This may play a role for partners' demand as well.

${ }^{27}$ The full set of results are available upon request.

${ }^{28}$ We compute the relative interest rates as the difference between the shadow rate in the euro area and that in the US $\left(i_{E A}-i_{U S}\right)$ calculated by $\mathrm{Wu}$ and Xia (2016).
} 
Table 2: Identification pattern based on zero and sign restrictions

\begin{tabular}{|c|c|c|c|c|c|c|}
\hline & $\begin{array}{l}\text { Aggregate } \\
\text { demand }\end{array}$ & $\begin{array}{l}\text { Aggregate } \\
\text { supply }\end{array}$ & $\begin{array}{l}\text { Global } \\
\text { demand }\end{array}$ & $\begin{array}{l}\text { Global } \\
\text { supply }\end{array}$ & $\begin{array}{l}\text { Foreign } \\
\text { exchange }\end{array}$ & $\begin{array}{l}\text { Monetary } \\
\text { policy }\end{array}$ \\
\hline & \multicolumn{6}{|c|}{ Short-run restrictions } \\
\hline GDP & + & + & + & + & $?$ & - \\
\hline HICP & + & - & + & - & - & - \\
\hline Interest rate & + & $?$ & $?$ & $?$ & $?$ & + \\
\hline Exchange rate & + & $?$ & $?$ & $?$ & + & + \\
\hline Import prices & $?$ & $?$ & $?$ & $?$ & - & $?$ \\
\hline \multirow[t]{2}{*}{ Foreign export prices } & 0 & 0 & + & - & $?$ & $?$ \\
\hline & \multicolumn{6}{|c|}{ Long-run restrictions } \\
\hline GDP & 0 & $?$ & 0 & $?$ & 0 & 0 \\
\hline HICP & $?$ & $?$ & $?$ & $?$ & $?$ & $?$ \\
\hline Interest rate & $?$ & $?$ & $?$ & $?$ & $?$ & $?$ \\
\hline Exchange rate & $?$ & $?$ & $?$ & $?$ & $?$ & $?$ \\
\hline Import prices & $?$ & $?$ & $?$ & $?$ & $?$ & $?$ \\
\hline Foreign export prices & $?$ & $?$ & $?$ & $?$ & $?$ & $?$ \\
\hline
\end{tabular}

shock; global supply shock; global demand shock; an exogenous exchange rate shock and a relative monetary policy shock. The data are quarterly covering the period 1992Q1-2016Q2 (max), transformed as log first differences (all except the interest rates). With the ECB policy rate being constrained by the ZLB over a significant portion of the sample under investigation, we use the shadow interest rate of Wu and Xia (2016) to represent both conventional and unconventional monetary policy actions.

\subsubsection{Identification pattern}

The restrictions we impose to identify the six shocks are outlined in Table 2 and generally reflect several relatively uncontroversial ideas - only supply shocks may affect output in the long run, demand and supply shocks are related to positive and negative correlation between real activity and inflation, respectively. Finally, our baseline specification assumes that domestic aggregate demand and supply shocks cannot influence foreign variables. The assumption that domestic demand and supply shocks cannot influence the rest of the world helps to isolate local, idiosyncratic economic shocks from those generated abroad. At country level in the euro area, individual member states can hardly influence the rest of the world. For that reason, we impose block exogeneity restrictions in that case, which prevent domestic demand and supply shocks from impacting foreign prices (see Appendix). Regarding the interpretation, domestic shocks refer to those events affecting the domestic economy only and not necessarily to all shocks generated domestically. At the aggregate euro area level however, domestic shocks may arguably influence the rest of the world and imposing block exogeneity in that case may be excessive. In order to test for 
that, we specify alternative patterns to separate domestic and foreign shocks.

In the short run, we assume that the domestic aggregate demand shock is related to a positive correlation between GDP and HICP whereas the domestic aggregate supply shock is related to a negative correlation. ${ }^{29}$ Similar to Forbes et al. (2015) we assume that a positive domestic demand shock (which may be more expansionary/less restrictive fiscal policies for instance) can be related to counter cyclical monetary policy response (an increase in the interest rates to curb possible excessive inflation) and exchange rate appreciation in nominal and real terms. ${ }^{30}$ Despite the appreciation following a domestic demand shock, HICP inflation increases because the boost to prices from stronger demand presumably outweighs the drag to prices from the appreciation and cheaper imports (Forbes et al., 2015). Domestic demand and supply shocks cannot influence world prices at all. In the short run that is ensured by imposing appropriate zero restrictions at impact, while further propagation of domestic shocks to the rest of the world is shut down by restricting the reduced form parameters of the model (see appendix for estimation details). ${ }^{31}$ The monetary policy shock is identified by assuming that positive shocks result in a decrease in GDP and inflation and appreciates the nominal exchange rate (Forbes et al., 2015 and Boeckx et al., 2014). The exogenous exchange rate shock is related to increases in both domestic import and consumer inflation (see An 2006 and Jovičić and Kunovac 2015). ${ }^{32}$ Finally, regarding the global shocks, we assume that global demand and supply shocks can influence domestic GDP and both domestic and global prices. In contrast to results for the UK presented in Forbes et al. (2015), we failed to identify global shocks solely based on the long run restriction without imposing short run sign restrictions explicitly on GDP and inflation. ${ }^{33}$

Finally, in order to identify the six shocks we also impose some long-run restrictions ensuring that only supply shocks, both domestic and foreign, can influence GDP in the long run. Indeed this is

\footnotetext{
${ }^{29}$ As in Forbes et al. (2015), we can consider the domestic supply shock as an increase in domestic productivity (due for instance to a changes in technology). This should increase GDP, while decreasing HICP (Shambaugh, 2008); resulting in a negative correlation between the two in the short run. In the long run instead a technology shock may still affect the output while prices will adjust to have market clearance.

${ }^{30}$ Moreover, if the country accumulated current account deficits and therefore experiences a negative net foreign asset position, it should have a trade surplus that offsets the interest payments on the external debt, and hence necessarily a real depreciation of the exchange rate (Lane and Milesi-Ferretti, 2004). This is the so-called transfer problem.

${ }^{31}$ Imposing block exogeneity in this context implies that domestic demand and supply shocks cannot influence foreign export prices. To implement that, one also prevents the exchange rate index and the (relative) monetary policy indicator to influence foreign prices through reduced form parameters in a VAR. To test the robustness of these, perhaps overly, strong assumptions we relax some of the restrictions and test alternative strategies to separate domestic and foreign shocks.

${ }^{32}$ In contrast to the previous section, the exchange rate shock is identified without the assumption of how foreign prices react to this shock. Relaxing this assumption speeds our sampling algorithm considerably but still produces pass-through coefficients comparable to those in the previous section.

${ }^{33}$ To impose sign and zero restrictions the two papers rely on different algorithms: Forbes (2015) uses one from Binning (2013) while we use algorithm proposed by Arias et al. (2014).
} 

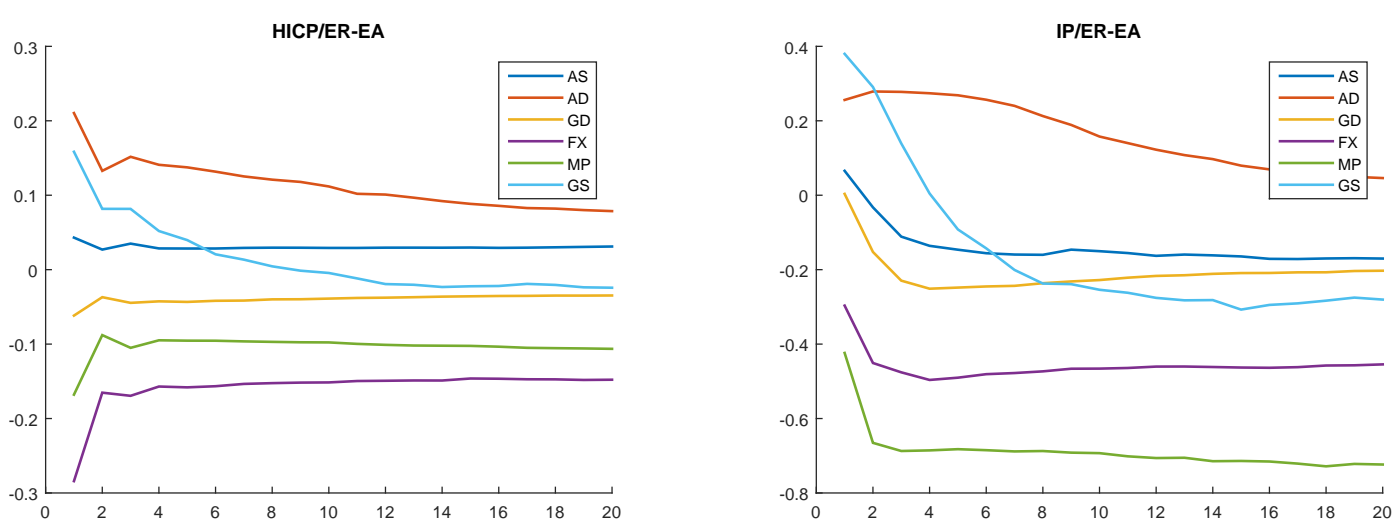

Figure 4: ERPT ratios for import deflator and HICP inflation in the euro area following each of the identified shocks - domestic aggregate demand (AD), aggregate supply (AS), global demand (GD), global supply (GS), exchange rate shock (FX), monetary policy (MP)

consistent with the idea that technology shocks can affect the productive capacity of an economy in the long run, and that prices will instead adjust over time to ensure that markets clear. Therefore the reaction of GDP to demand, monetary and exchange rate shock is only temporary in our specification. The full set of impulse responses are given in the appendix. Impulse responses are normalized to reflect $1 \%$ appreciation after 4 quarters for each identified shock.

\subsubsection{Results}

Figure 4 shows our shock dependent pass-through measure for the euro area - ERPT ratios for import and consumer price inflation. ${ }^{34}$ Ratios are calculated as a change in inflation divided by the change in the exchange rate following each of the identified shocks.

Our results suggest that exchange rate changes driven by monetary policy and exogenous exchange rate shocks result in the highest ERPT ratios, both for import and consumer price inflation. The ERPT ratios for the two shocks to import prices are much larger in magnitude with respect to that for HICP, as expected. Global supply shocks seem to have no effect on pass-through to HICP in the longer run, while they do affect that to import prices, however only with a small posterior probability (Table 4). Interestingly, domestic demand shocks are related to pass-through with the "wrong" sign - an exchange rate appreciation following a demand shock may increase domestic prices. In other words, the increase in prices after demand shocks may offset a standard negative impact of exchange rate appreciation on prices.

\footnotetext{
${ }^{34}$ Results for EA monetary policy in standard (non relative) terms is given at Figure 26 in the appendix.
} 
The fact that ERPT depends on the shock that triggers the exchange rate movement suggests that the overall magnitude of pass-through varies with the particular composition of economic shocks governing exchange rate dynamics. In order to assess the relative importance of individual shocks for overall pass-through to inflation, we rely on a historical decomposition of the nominal effective exchange rate resulting from our identified VAR. Overall ERPT is therefore calculated as a linear combination of individual pass-through ratios over all shocks, weighted by the relative importance of that shock in the historical decomposition of the exchange rate (details are given in appendix in section A.3):

$$
\operatorname{erpt}_{t}^{j}=\sum_{k} \theta_{k} \cdot \widetilde{y_{j t}^{k}}
$$

$\theta_{k}$ denoting the ERPT ratios at 1-year horizon and $\widetilde{y_{j t}^{k}}$ is the relative contribution of the $k$ th structural shock to the $j$ th variable at period $t$. The ERPT measure calculated in this way is time-varying by construction. Time variation here is a natural consequence of the different composition of shocks hitting the euro area economy over time.

Figure 5 shows the time varying shock-dependent ERPT to import and consumer price inflation in the euro area based on ERPT ratios on 1-year horizons. ${ }^{35}$ Our pass-through measure calculated from a full set of pass-through ratios is rather volatile and reflects the varying composition of shocks behind the euro exchange rate. The shock-dependent ERPT measure suggests that if we take into account all the shocks, including positive domestic demand ones, import price ERPT is weak during the very recent period. This may be due to the current composition of shocks hitting the euro area. For instance, the decline of oil prices may have played a role (making foreign export prices decline, as a shock in global supply) together with the positive influence of aggregate demand shocks, while relative monetary policy and exchange rate shocks have been not large enough to offset this effect.

The posterior significance for each of the pass-through ratios for the aggregate euro area is shown in Tables 3-4 in the appendix. Based on our baseline identification scheme it seems that for both import and consumer prices two shocks matter the most - monetary policy and exogenous exchange rate shocks. For import prices our results suggest that exchange rate pass-through is of the expected sign for all identified shocks, but only for the exchange rate and monetary policy with relatively high posterior probability. Regarding consumer price inflation, again the same two shocks seem to be the most important.

\footnotetext{
${ }^{35}$ Figure 27 provides the shock dependent ERPT in case of simple/non-relative monetary policy.
} 


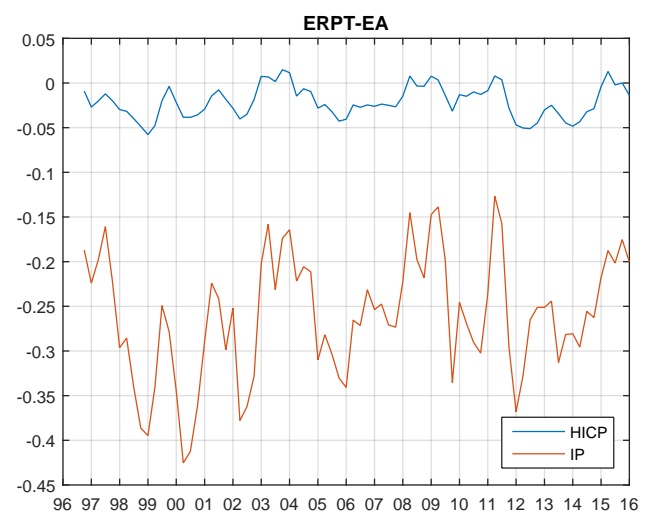

Figure 5: Time varying ERPT in the euro area based on the identified shocks

Country-level analysis We also look at the ERPT ratios and shock-dependent ERPTs for the four major euro area countries. The ratios are given in Figure 13 for HICP and Figure 14 for IP. ${ }^{36}$ Again, our focus is on the corrected estimates of exchange rate pass-through. The relative monetary policy shock and the exogenous exchange rate shock are important for both HICP and IP and in every country. The posterior significance is broadly in line with that for the euro area (country-specific results are in Table 512 in Appendix). The ERPT ratios for the relative monetary policy shock are in magnitude very similar each other and to the euro area; while for the other significant shock, i.e. to exchange rates, the ratio is smaller for the single member states than for the aggregate. Overall ERPT ratios for import prices are instead larger in Italy or Spain than in the other considered members or the whole euro area, confirming the previous results. Concerning the shock-dependent ERPTs, while the results for the consumer prices are comparable to the euro area, for import prices the values look slightly larger in the single countries in the recent quarters with the notable exception of France. This may be due to the larger positive effect of aggregate demand shocks for this country compared to the other members (see Figure 14).

\subsection{Robustness checks}

Alternative identification patterns In order to assess the reliability of our results we perform various robustness checks. ${ }^{37}$ First we relaxed some of the restrictions imposed onto impulse response function (Table 2) and compared the estimated shock-dependent pass-through ratios to those resulting from our baseline specification. Most importantly, in our baseline specification, pass-through was proven to be important when the exchange rate movement was triggered by two shocks - monetary policy

\footnotetext{
${ }^{36}$ The results for the setup with the simple EA monetary policy are available upon request.

${ }^{37}$ All the details related to specifications outlined here are available upon request.
} 
and exchange rate. However, this was not surprising because we explicitly imposed the signs on the responses of the euro nominal effective exchange rate following these two shocks. In order to test how our results depend on these restrictions we specify an alternative VAR and relax the restrictions on how the monetary policy shock influences exchange rate ${ }^{38}$. In that case, exchange rate pass-through following a monetary policy shock was not significant at all suggesting that our results heavily depend on the identification scheme imposed onto impulse responses. ${ }^{39}$ This seems to be related to the exchange rate fundamentals disconnect. Evidence of the role of monetary policy for exchange rates has been only found for the non-standard measures as an exogenous rise in the ECB's balance sheet (Boeckx et al., 2014).

Alternative specifications of small-country assumption Our identification strategy assumes that domestic aggregate demand and supply shocks cannot influence foreign exporters' prices when modelling the pass-through both for the aggregate euro area economy and at the country level. At the aggregate euro area level, however, domestic shocks may arguably influence the rest of the world and imposing block exogeneity in that case may indeed be excessive. In order to test for that, we attempted to isolate domestic from foreign shocks by adopting two additional strategies. First, we relaxed only restrictions on VAR parameters preventing the influence of euro area variables on foreign prices. After that we relaxed both restrictions on VAR parameters and those at impact preventing domestic demand and supply shocks from influencing foreign prices. For both alternative strategies our estimates of ERPT remained largely unchanged.

\section{Does the median of impulse responses represent the constrained posterior distribution}

properly? In this paper we report posterior medians of the impulse responses and historical decomposition to summarize the results of the estimated models. It has been well recognised that this approach has some important shortcomings (Fry and Pagan 2011). Most importantly, the median response represents no single structural model and therefore has no structural interpretation unless pointwise median impulse responses belong to the same structural model - a highly unlikely event. This has important implications for our time varying ERPT measure based on impulse responses and historical decomposition. To clarify, although for a single posterior draw of parameters the historical decomposition does

\footnotetext{
${ }^{38}$ This is one of the identifications also in Bobeica and Jarocinski (2016) for the Cholesky and the implementation of Corsetti et al. (2014).

${ }^{39}$ This is quite in line with the outcomes for the euro area if the response of exchange rate to a monetary policy shock is left unrestricted (ECB, 2016).
} 
add up properly - it is equal to observed values of exchange rate, the same does not hold true for the median historical decomposition (Figures 22-25). A possible solution for that problem proposed by Fry and Pagan (2011) is to find a single model with impulse response functions that are as close to the observed median impulse response as possible. This proposal is independent from the statistical paradigm adopted - Bayesian or classical. However it is easier to implement under a standard frequentist approach relying on a single point estimate of a vector of parameters of interest. On the other hand, to implement their proposal under the Bayesian framework one needs to account for both parameter uncertainty and the model uncertainty related to the implementation of the sign restrictions methodology. To do so, for each posterior draw of the reduced-form parameters one may need to draw a large number of orthogonal matrices $Q$ that satisfy both sign and zero restrictions imposed (see appendix). This strategy may become infeasible when implemented in a specification dealing with a large number of imposed restrictions. In our case, we identified a full set of structural shocks with a large number of zero and sign restrictions and, therefore, largely for economical reasons we rely on the posterior median when presenting our main results.

Relative vs standard monetary policy We also ran our baseline specification for the euro area with the standard (non-relative) shadow interest rate. Most importantly, exchange rate pass-through following monetary policy is weaker in this case compared to a model with relative monetary policy. This is true for both the euro area as a whole and for four countries under analysis. It seems that the relative monetary policy indeed captures an interesting part of the transmission of monetary policy from the US, affecting both exchange rates and the euro area inflation itself. This may influence the reaction to global shocks as well. The indirect effect of monetary policy coming from the US can somehow reduce the positive contribution of recent unconventional monetary policy on inflation in the euro area via the transmission to the exchange rate ${ }^{40}$ (see the historical decompositions of the NEER in Figure 28 for the specification with non-relative monetary policy and Figure 29 for the one with relative monetary policy).

\section{Conclusion}

In this paper we provide some fresh evidence on exchange rate pass-through to inflation in the euro area. For that purpose we move away from a standard approach using Cholesky-identified VARs and

\footnotetext{
${ }^{40}$ In the NEER decomposition, in the case of the specification with standard monetary policy, the role of the latter is more negative in magnitude since mid-2015, while the global supply seems much less relevant.
} 
use Bayesian VARs with identification based on a combination of zero and sign restrictions. In line with related literature, our results point to a large but volatile pass-through to import prices and overall very small pass-through to consumer inflation in the euro area. We also emphasize that pass through in the euro area may crucially depend on the composition of economic shocks underlying the movement in exchange rate. However, consistent with previous research, it may be difficult to find a single identification scheme linking exchange rate dynamics and macroeconomic fundamentals in an intuitive and robust fashion. Indeed, our main results on the relative importance of individual shocks for the overall ERPT coefficient hold true only conditional on our preferred identification scheme. Regardless of the specification used to identify the sources of exchange rate movements, our results indicate that exchange rate pass-through in the euro area may be more difficult to measure than previously considered. The exchange rate pass-through being shock-dependent, its historical estimates may be of limited help when predicting pass-through effects in the future without strong assumptions on the composition of shocks underlying the nominal exchange rate. 


\section{References}

[1] An, L., 2006. "Exchange Rate Pass-Through: Evidence Based on Vector Autoregression with Sign Restrictions," MPRA Paper 527, University Library of Munich, Germany.

[2] An, L. and Wang, J., 2011. "Exchange Rate Pass-through: Evidence Based on Vector Autoregression with Sign Restrictions", Federal Reserve Bank of Dallas Working Paper No. 70.

[3] Arias, J. E. \& Rubio-Ramirez, J. F. \& Waggoner, D. F., 2014. "Inference Based on SVARs Identified with Sign and Zero Restrictions: Theory and Applications," International Finance Discussion Papers 1100, Board of Governors of the Federal Reserve System (U.S.).

[4] Bauer, M. D., and Rudebusch G. D. 2015 "Monetary Policy Expectations at the Zero Lower Bound." Federal Reserve Bank of San Francisco, Working Paper.

[5] Binning, A. 2013. "Underidentified SVAR models: A framework for combining short and long-run restrictions with sign-restrictions," Working Paper 2013/14, Norges Bank.

[6] Bluwstein, K. and Canova, F. 2016. "Beggar-thy-neighbor? The international effects of ECB unconventional monetary policy measures ", mimeo.

[7] Boeckx, J., Dossche, M., and Peersman, G. 2014. "Effectiveness and Transmission of the ECB's Balance Sheet Policies ". CESifo Working Paper Series 4907, CESifo Group Munich.

[8] Campa, J.M., Goldberg, L., 2005. "Exchange Rate Pass-Through into Import Prices," The Review of Economics and Statistics, MIT Press, vol. 87(4), pages 679-690, November.

[9] Ca’ Zorzi, M., Hahn, E., Sánchez, M., 2007. "Exchange Rate Pass-Through in Emerging Markets," The IUP Journal of Monetary Economics, IUP Publications, vol. 0(4), pages 84-102, November.

[10] Chaboud A. P. and Wright J., 2005. "Uncovered interest parity: it works, but not for long, " Journal of International Economics, 2005, vol. 66, issue 2, pages 349-362.

[11] Chinn, M. and G. Meredith. 2005. "Testing Uncovered Interest Parity at Short and Long Horizons during the Post-Bretton Woods Era." NBER Working Paper No. 11077.

[12] Choudhri, E. U., Faruqee, H., \& Hakura, D. S. 2005. "Explaining the exchange rate pass-through in different prices ". Journal of International Economics, 65, 349374. 
[13] Comunale, M. \& Hessel, J. 2014, "Current Account Imbalances in the Euro Area: Competitiveness or Financial Cycle?" DNB Working paper n.443.

[14] Comunale, M., 2015a. "Euro-Dollar Polarization and Heterogeneity in Exchange Rate PassThroughs within the Euro Zone," CEIS Research Paper 333, Tor Vergata University, CEIS, revised 13 Mar 2015.

[15] Comunale, M., 2015b. "Financial cycle measures for 41 countries: A new database," Occasional Paper Series, Bank of Lithuania, No.09/2015.

[16] Corsetti G., Dedola L. \& Leduc S., 2005. "DSGE models of high exchange-rate volatility and low pass-through, "International Finance Discussion Papers 845, Board of Governors of the Federal Reserve System (U.S.).

[17] Corsetti, G., Dedola, L. and Leduc, S., 2009. "Optimal Monetary Policy and the.Sources of LocalCurrency Price Stability", in International Dimension of Monetary Policy edited by Jordi Gali and Mark Gertler, Chicago University Press, 2009, 319-367.

[18] Corsetti, G., Dedola, L., and Leduc, S.(2014. "The international dimension of productivity and demand shocks in the US economy. Journal of the European Economic Association,12(1):153\{176.

[19] Devereux, M., B, and Genberg, H., 2007. "Currency appreciation and current account adjustment," Journal of International Money and Finance, Elsevier, vol. 26(4), pages 570-586, June.

[20] de Walque, G., F. Smets, and R. Wouters. 2005. "An estimated two- country DSGE model for the Euro area and the U.S. economy ". National Bank of Belgium and Bank of Canada. Mimeo.

[21] Francis X., D. and Rudebusch., G. D., 2013. "Yield Curve Modeling and Forecasting". Princeton, NJ: Princeton University Press.

[22] Di Mauro F., Rüffer R. and I. Bunda, 2008. "The changing role of the exchange rate in a globalised economy", ECB Occassional Paper 94.

[23] ECB, 2014. "The ECB's forward guidance", ECB Monthly Bulletin, April 2014.

[24] ECB, 2015. "The international role of euro", July 2015.

[25] ECB, 2016. "Low inflation in the euro area: causes and consequences", Forthcoming ECB Occasional Paper. 
[26] Engel, C., 2013. "Exchange Rates and Interest Parity", NBER Working Paper, No. 19336, August.

[27] Farrant, K.\& Peersman, G., 2006. "Is the Exchange Rate a Shock Absorber or a Source of Shocks? New Empirical Evidence," Journal of Money, Credit and Banking, Blackwell Publishing, vol. 38(4), pages 939-961, June.

[28] Faruqee, H. 2005. "Exchange-rate pass-through in the euro area ". IMF Staff Papers Vol. 53, No. 1. Previous version available as IMF Working Paper 04/14.

[29] Forbes, K., 2015. "Much ado about something important: How do exchange rate movements affect inflation?". Speech given at 47th Money, Macro and Finance Research Group Annual Conference, Cardiff, 11 September 2015.

[30] Forbes, K., I. Hjortsoe and T. Nenova, 2015. "The Shocks Matter: New Evidence on Exchange Rate Pass-Through.”, Bank of England, Discussion Paper No. 43 November 2015.

[31] Fry, R. and Pagan, A.. 2011. "Sign Restrictions in Structural Vector Autoregressions: A Critical Review." Journal of Economic Literature, 49(4): 938-60.

[32] Glick, R. \& Leduc, S., 2015. "Unconventional monetary policy and the dollar: conventional signs, unconventional magnitudes," Working Paper Series 2015-18, Federal Reserve Bank of San Francisco.

[33] Goldberg, L. \& Tille, C., 2006. "The International Role of the Dollar and Trade Balance Adjustment," NBER Working Papers 12495, National Bureau of Economic Research, Inc.

[34] Goldberg, L. \& Tille, C., 2009. "Macroeconomic interdependence and the international role of the dollar," Journal of Monetary Economics, Elsevier, vol. 56(7), pages 990-1003, October.

[35] Goldberg, P.K. and Knetter M.,1997. "Goods Prices and Exchange Rates: What Have We Learned?" Journal of Economic Literature 35: 1243-72.

[36] Gopinath, G., Itskhoki, O. and Rigobon, R. 2010, "Currency choice and exchange rate passthrough", American Economic Review, Vol. 100(1), pp. 304-336.

[37] Hahn, E., 2003. "Pass-through of external shocks to euro area inflation," Working Paper Series 0243, European Central Bank. 
[38] Horioka, C.Y. \& Ford, N., 2016. "A Possible Explanation of the 'Exchange Rate Disconnect Puzzle': A Common Solution to Three Major Macroeconomic Puzzles?," ISER Discussion Paper 0977, Institute of Social and Economic Research, Osaka University.

[39] Iossifov, P., J. Podpiera, 2014. "Are Non-Euro Area EU Countries Importing Low Inflation from the Euro Area", International Monetary Fund, WP/14/191.

[40] Jarocinski, M. and Bobeica, E., 2016. "Drivers of euro area inflation since the crisis", mimeo.

[41] Jovičić, G. \& Kunovac D., 2015. "What Drives Inflation in a Small European Economy: The Case of Croatia", Conference paper, Dubrovnik economic conference organized by Croatian national bank 2015.

[42] Kim, Y., 1990. "Exchange Rates and Import Prices in the United States: A Varying-Parameter Estimation of Exchange-Rate Pass-Through," Journal of Business 83 Economic Statistics, American Statistical Association, vol. 8(3), pages 305-15, July.

[43] Knetter M.,1989. "Price Discrimination by U.S. and German Exporters", American Economic Review, American Economic Association, vol. 79(1), pages 198-210, March.

[44] Koop, G.\& Korobilis, D., 2009. "Bayesian Multivariate Time Series Methods for Empirical Macroeconomics", Working Paper Series 47_09, The Rimini Centre for Economic Analysis, revised Jan 2009.

[45] Krippner, L. 2013a, "Measuring the stance of monetary policy in zero lower bound environments". Economics Letters, 118(1), 135-138.

[46] Krippner, L. 2013b, "A Tractable Framework for Zero Lower Bound Gaussian Term Structure Models". Australian National University, CAMA Working Paper 49/2013.

[47] Krippner, L. 2014, "Measuring the stance of monetary policy in conventional and unconventional environments", Australian National University CAMA Working Paper 6/2014.

[48] Krugman P.,1987. "Pricing to market when the exchange rate changes", NBER Working Paper No. 1926.

[49] Kunovac, D., and Kotarac, K., 2015., "BVARs with block exogeneity and sign and zero restrictions" MATLAB Toolbox, Modelling department, Croatian national bank 
[50] Lane, P. R., Milesi-Ferretti, G. M. 2004. "The transfer problem revisited: Net foreign assets and real exchange rates", Review of Economics and Statistics, 86(4), pp. 841-857.

[51] Lombardi, M. and Zhu F. 2014 "A shadow policy rate to calibrate US monetary policy at the zero lower bound", Working paper, BIS, No.452.

[52] Marston, R., 1990. "Pricing to Market in Japanese Manufacturing", Journal of International Economics, 29, pp. 217-236.

[53] Meese, R. A., and Rogoff, K. 1983, "Empirical Exchange Rate Models of the Seventies: Do They Fit Out of Sample?" Journal of International Economics, vol. 14, no. 1-2 (February), pp. 3-24.

[54] McCarthy, J., 2007. "Pass-Through of Exchange Rates and Import Prices to Domestic Inflation in Some Industrialized Economies", Eastern Economic Journal, Eastern Economic Association, vol. 33(4), pages 511-537, Fall.

[55] Obstfeld, M. and K. Rogoff, 2000. "The Six Major Puzzles in International Macroeconomics: Is There a Common Cause?" NBER Macroeconomics Annual 15: 339-90.

[56] Osbat C. and M. Wagner, 2006. "Sectoral Exchange Rate Pass-Through in the Euro Area", mimeo.

[57] Peersman, G. 2012. "Effectiveness of Unconventional Monetary Policy at the Zero Lower Bound," 2012 Meeting Papers 400, Society for Economic Dynamics.

[58] Rogoff, K.S. \& Stavrakeva, V., 2008. "The Continuing Puzzle of Short Horizon Exchange Rate Forecasting," NBER Working Papers 14071, National Bureau of Economic Research, Inc.

[59] Rubio-Ramirez, J. F. \& Waggoner, D. F. \& Zha, T., 2010. "Structural Vector Autoregressions: Theory of Identification and Algorithms for Inference," Review of Economic Studies, Oxford University Press, vol. 77(2), pages 665-696.

[60] Saiki, A., 2011. "Exchange Rate Pass-Through and Monetary Integration in the Euro Area", De Nederlandsche Bank Working Paper No. 308, August 2011.

[61] Schröder, M., \& Hüfner, F. P., 2002. "Exchange rate pass-through to consumer prices: a European perspective, ZEW Discussion Papers 02-20, ZEW - Zentrum für Europäische Wirtschaftsforschung / Center for European Economic Research. 
[62] Sarno, L., 2005. "Viewpoint: Towards a solution to the puzzles in exchange rate economies: where do we stand?", Canadian Journal of Economics 38(3), 673-708.

[63] Sarno, L. and M. Taylor, 2002. "The Economics of Exchange Rates ",Cambridge and New York: Cambridge University Press.

[64] Sarno L., Schneider P. and Wagner C. 2009. "Theoretical and Empirical Properties of Foreign Exchange Risk Premia", mimeo.

[65] Sarno L., Schneider P. and Wagner C. 2012. "Properties of foreign exchange risk premiums," Journal of Financial Economics, Elsevier, vol. 105(2), pages 279-310.

[66] Shambaugh, J., 2008. "A new look at pass-through", Journal of International Money and Finance, No. 27, 560-591.

[67] Taylor J. B., 2000. "Low Inflation, Pass-through and the Pricing Power of Firms", European Economic Review, 44, pp. 1389-1408.

[68] Wolden Bache I. 2006, "assessing the structural VAR approach to exchange rate pass-through", Computing in Economics and Finance 2006 309, Society for Computational Economics.

[69] Wu, J. C. and Xia, F. D., 2016. "Measuring the Macroeconomic Impact of Monetary Policy at the Zero Lower Bound ", Journal of Money, Credit and Banking, Vol. 48, No. 2-3 (March-April 2016) 


\section{A Appendix}

\section{A.1 Structural VAR with block exogeneity: Bayesian approach}

Let us consider a structural vector autoregression (SVAR) model $^{41}$

$$
A_{0} y_{t}=\mu+A_{1} y_{t-1}+\ldots+A_{k} y_{t-k}+\varepsilon_{t}, \quad t=1, \ldots, T
$$

where $y_{t}$ is an $n \times 1$ vector of observed variables, the $A_{j}$ are fixed $n \times n$ coefficient matrices with invertible $A_{0}, \mu$ is $n \times 1$ fixed vector and $\varepsilon_{t}$ are economic shocks with zero mean and covariance matrix $I_{n}$. The reduced form VAR model obtained from (1) is

$$
y_{t}=c+B_{1} y_{t-1}+\ldots+B_{k} y_{t-k}+u_{t}, \quad t=1, \ldots, T
$$

where $B_{j}=A_{0}^{-1} A_{j}, c=A_{0}^{-1} \mu$ and $u_{t}=A_{0}^{-1} \varepsilon_{t}$ and thus $E\left(u_{t} u_{t}^{\prime}\right)=\Omega=\left(A_{0}^{\prime} A_{0}\right)^{-1}$. Model (2) can be written in a compact form more convenient for Bayesian simulation of reduced form parameters:

$$
y_{t}=X_{t}^{\prime} \beta+u_{t}
$$

where

$$
X_{t}^{\prime}=I_{n} \otimes\left[1, y_{t-1}^{\prime}, \ldots, y_{t-k}^{\prime}\right]\left(n \times\left(k n^{2}+n\right)\right), \quad \beta=\operatorname{vec}\left(\left[c B_{1} \ldots B_{k}\right]^{\prime}\right)\left(\left(k n^{2}+n\right) \times 1\right) .
$$

Block exogeneity is a common assumption when modelling the transmission of economic shocks between a large and a small economy using VARs. It refers to a certain type of restrictions where shocks originating in the large economy (or foreign block from a small country point of view) can influence the small economy, but not the other way around. To illustrate that let $y_{1 t}$ be an $n_{1}$ dimensional vector of foreign variables and $y_{2 t}$ an $n_{2}=n-n_{1}$ dimensional vector of domestic variables so $y_{t}$ can be decomposed as $y_{t}^{\prime}=\left[y_{1 t}^{\prime}, y_{2 t}^{\prime}\right]$. In order to account for block exogeneity matrices $A_{j}$ from (1) need to be lower triangular:

$$
A_{j}=\left[\begin{array}{cc}
A_{11}^{j} & 0 \\
A_{21}^{j} & A_{22}^{j}
\end{array}\right], \quad j=0, \ldots, k,
$$

\footnotetext{
${ }^{41}$ Identification based on sign and zero restrictions is implemented using a MATLAB Toolbox by Kunovac and Kotarac (2015). The Toolbox and code used in this paper are available upon request.
} 
and it can be shown that reduced form coefficient matrices $B_{j}$ inherit the block exogeneity form so that:

$$
B_{j}=\left[\begin{array}{cc}
B_{11}^{j} & 0 \\
B_{21}^{j} & B_{22}^{j}
\end{array}\right], \quad j=1, \ldots, k
$$

In order to implement the block exogeneity assumption both impact matrix $A_{0}$ and VAR coefficients need to be restricted. The impact matrix is restricted by placing zeros so that a small country cannot affect a big country at $t=0$. In order to prevent the propagation of domestic (small economy) shocks through the foreign block beyond the impact $(h=1,2, \ldots)$, some parameters of the VAR need to be restricted as well. Within the Bayesian framework this can be achieved by assuming an appropriate prior distribution for parameters to be restricted. The natural conjugate (i.e. normal inverse Wishart) prior is not suitable for this purposes as it assumes that the prior covariances of coefficients in any two equations are proportional to each other (see Koop and Korobilis, 2010). However, the Independent normal inverse Wishart will serve the purpose. Under the prior reduced-form coefficients and the error covariance matrix are independent:

$$
\beta \sim N\left(\underline{\beta}, \underline{V}_{\beta}\right), \quad \Omega \sim I W(\underline{M}, \underline{\gamma})
$$

and the conditional posterior distributions $p(\beta \mid y, \Omega)$ and $p(\Omega \mid y, \beta)$ now have the following form

$$
\beta\left|y, \Omega \sim N\left(\bar{\beta}, \bar{V}_{\beta}\right), \quad \Omega\right| y, \beta \sim I W(\bar{M}, \bar{\gamma})
$$

where

$$
\bar{V}_{\beta}=\left(\underline{V}_{\beta}^{-1}+\sum_{t=1}^{T} X_{t} \Omega^{-1} X_{t}^{\prime}\right)^{-1}, \quad \bar{\beta}=\bar{V}_{\beta}\left(\underline{V}_{\beta}^{-1} \underline{\beta}+\sum_{t=1}^{T} X_{t} \Omega^{-1} y_{t}\right)
$$

and

$$
\bar{\gamma}=T+\underline{\gamma}, \quad \bar{M}=\underline{M}+\sum_{t=1}^{T}\left(y_{t}-X_{t}^{\prime} \beta\right)\left(y_{t}-X_{t}^{\prime} \beta\right)^{\prime} .
$$

To restrict VAR parameters needed for block exogeneity we assume zero mean priors with extremely small variance for all the small-country parameters in every equation of the big country block. In other words, if we want to restrict the $j$-th element of $\beta$ we can set $(\underline{\beta})_{j}=0$ and $\left(\underline{V}_{\beta}\right)_{j j}=\varepsilon$ where $\varepsilon$ is some small positive number. By doing so we attach dominant weight to the (zero mean) prior parameters when calculating the posterior. In this way sample information is largely ignored as the posteriors of 
these coefficients will be predominantly influenced by the prior. A sample from the posterior of the reduced form parameters and residual covariance matrix is drawn by using a Gibbs sampler (see for example Koop and Korobilis, 2010).

In this paper structural shocks are identified by imposing both sign and zero restrictions on the impulse response functions (IRFs). Sign restrictions alone are efficiently implemented by iterating the steps suggested in Rubio-Ramirez, Waggoner and Zha (2010). In short, for each posterior draw of the reduced form parameters (regression parameters and covariance matrix) they first calculate an uniformly distributed orthogonal matrix $Q$. After that they multiply the Cholesky based impact matrix $A_{0}$ by the orthogonal matrix $Q$ and construct the resulting IRFs. If impulse responses satisfy the sign restrictions the posterior draw is accepted. Otherwise they repeat the procedure with a new posterior draw of reduced form parameters. If a model has both sign and zero restrictions imposed the algorithm outlined above cannot be applied in that case - the impulse responses based on $Q A_{0}$ almost surely do not satisfy zero restrictions. To cope with that problem Arias, Rubio-Ramirez, Waggoner (2014) propose the algorithm that produces an orthogonal $Q$ such that $Q A_{0}$ do satisfy the zero restrictions at various horizons of the IRF. Sign restrictions are checked in similar fashion as before. Important to say, beside the details of the algorithm ARRW also provide a rigorous proof of validity of their algorithm from the Bayesian perspective. They show that their algorithm really draws from the posterior distribution of structural parameters conditional on the sign and zero restrictions, which is a property that other identification strategies of the problem fail to satisfy.

\section{A.2 The corrected ERPT estimates}

In order to make our estimates of ERPT for the aggregate euro area and those for the individual member states mutually comparable, we look at the corrected ERPT coefficients. The correction only adjusts the baseline estimates of ERPT for each member states so to account for both the intra and extra euro area trade component in the NEER for each member state of the euro area. The correction is conducted as explained in this section.

First, the nominal effective exchange rate (NEER) of the euro we use is defined as the geometric weighted average of a basket of bilateral exchange rates:

$$
N E E R_{t}=\prod_{i}\left(\frac{R_{t}^{i}}{R_{0}^{i}}\right)^{w_{i}}
$$


$R_{t}^{i}$ being a price of the home currency at time $t$ in terms of the currency of the $i^{\text {th }}$ country and $\sum_{i} w_{i}=1$.

The rate of change in the NEER may be approximated by a weighted arithmetic mean of changes in bilateral exchange rates for small changes in NEER (whenever $N E E R_{t}$ is close to $N E E R_{t-1}$ and $R_{t}^{i}$ close to $\left.R_{t-1}^{i}\right)$ :

$$
\frac{N E E R_{t}-N E E R_{t-1}}{N E E R_{t-1}} \approx \log \frac{N E E R_{t}}{N E E R_{t-1}}=\sum_{i} w_{i} \cdot \log \frac{R_{t}^{i}}{R_{t-1}^{i}} \approx \sum_{i} w_{i} \cdot \frac{R_{t}^{i}-R_{t-1}^{i}}{R_{t-1}^{i}}
$$

The nominal exchange rate for each member state can therefore be decomposed into two sums - one pertaining to other member states with weights reflecting intra euro area trade and the second one, pertaining to those trading partners outside the euro area. The rate of change in the NEER of a euro area country (labelled $c$ ) may be written:

$$
\begin{aligned}
\frac{N E E R_{t}^{c}-N E E R_{t-1}^{c}}{N E E R_{t-1}^{c}} & \approx \sum_{i \in I \backslash\{c\}} w_{i}^{c} \cdot \frac{R_{t}^{i c}-R_{t-1}^{i c}}{R_{t-1}^{i c}}+\sum_{j \in J} w_{j}^{c} \cdot \frac{R_{t}^{j c}-R_{t-1}^{j c}}{R_{t-1}^{j c}} \\
& =\sum_{j \in J} w_{j}^{c} \cdot \frac{R_{t}^{j c}-R_{t-1}^{j c}}{R_{t-1}^{j c}}
\end{aligned}
$$

where $I$ denotes a set of euro area countries, $J$ is a set of non-euro area countries and $c \in I$ is the selected euro area country. Now, let $\alpha=\sum_{j \in J} w_{j}^{c}$ denote the overall share of extra euro area trade in total trade of the country of interest. Then, from:

$$
\begin{aligned}
\frac{N E E R_{t}^{c}-N E E R_{t-1}^{c}}{N E E R_{t-1}^{c}} & \approx \alpha \cdot \sum_{j \in J} \frac{w_{j}^{c}}{\alpha} \cdot \frac{R_{t}^{j c}-R_{t-1}^{j c}}{R_{t-1}^{j c}}=\alpha \cdot \sum_{j \in J} \widetilde{w_{j}^{c}} \cdot \frac{R_{t}^{j c}-R_{t-1}^{j c}}{R_{t-1}^{j c}} \text { and } \\
\frac{N E E R_{t}^{E A}-N E E R_{t-1}^{E A}}{N E E R_{t-1}^{E A}} & \approx \sum_{j \in J} w_{j}^{E A} \cdot \frac{R_{t}^{j E A}-R_{t-1}^{j E A}}{R_{t-1}^{j E A}}
\end{aligned}
$$

and assuming $w_{j}^{E A} \approx \widetilde{w_{j}^{c}}$ for all $j$, we have an approximate relationship between changes in NEERs of each member states and the total NEER of the euro area:

$$
\frac{N E E R_{t}^{c}-N E E R_{t-1}^{c}}{N E E R_{t-1}^{c}} \approx \alpha \cdot \frac{N E E R_{t}^{E A}-N E E R_{t-1}^{E A}}{N E E R_{t-1}^{E A}} .
$$

If the ERPT coefficient is defined as a measure of how inflation rate changes with the change in exchange 
rate $\left(\frac{\partial \pi_{t}}{\partial n_{t}}\right)$ we may now relate the ERPT to inflation for each member state from two exchange rates $N E E R^{c}$ and $N E E R^{E A}$ :

$$
\frac{\partial \pi_{t}^{c}}{\partial n_{t}^{E A}} \approx \alpha \cdot \frac{\partial \pi_{t}^{c}}{\partial n_{t}^{c}}
$$

$\pi_{t}^{c}$ denoting inflation in country $c, n_{t}^{E A}$ and $n_{t}^{c}$ the change in the two exchange rates. In this paper we estimate $\frac{\partial \pi_{t}^{c}}{\partial n_{t}^{c}}$ directly from the estimated VARs and then construct the corrected ERPT coefficients

$\alpha \cdot \frac{\partial \pi_{t}^{c}}{\partial n_{t}^{c}}\left(\approx \frac{\partial \pi_{t}^{c}}{\partial n_{t}^{E A}}\right)$ in order to make the estimated pass-through coefficients for the euro area as a whole and those for each member states mutually comparable. The scaling constants $(\alpha)$ used for correction purposes for each country are calculated as an average share of extra euro area trade in total trade over period 1998-2013.

\section{A.3 Time varying ERPT}

Let $y_{j t}$ be the $j$ th variable in a VAR model. Contribution of the $k$ th structural shock to the $j$ th variable at time $t$ can be calculated as:

$$
y_{j t}^{k}=\sum_{i=0}^{t-1} \psi_{j k, i} \cdot v_{k, t-i}
$$

where $v_{k, t-i}$ is the value of the $k$ th structural shock at time $t-i$, and $\psi_{j k, i}$ is response of $j$ th variable to shock $k$ at horizon $i$. The relative contribution of the $k$ th structural shock to the $j$ th variable is calculated as:

$$
\widetilde{y_{j t}^{k}}=\frac{\left|y_{j t}^{k}\right|}{\sum_{k}\left|y_{j t}^{k}\right|} .
$$

Now if $\theta_{k}$ denote the ERPT ratios for import and consumer price inflation at 1-year horizon, then shock dependent ERPT to import and consumer price inflation at time $t$ is calculated from:

$$
\operatorname{erpt}_{t}^{j}=\sum_{k} \theta_{k} \cdot \widetilde{y_{j t}^{k}} .
$$




\section{A.4 Figures}

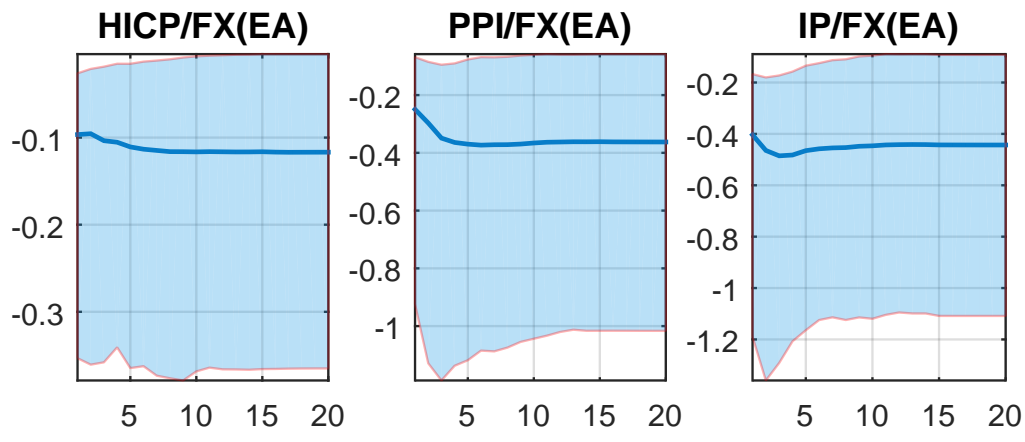

Figure 6: ERPT ratios for the euro area. Impulse responses to one unit shock to exchange rate, median together with $68 \%$ interval. 

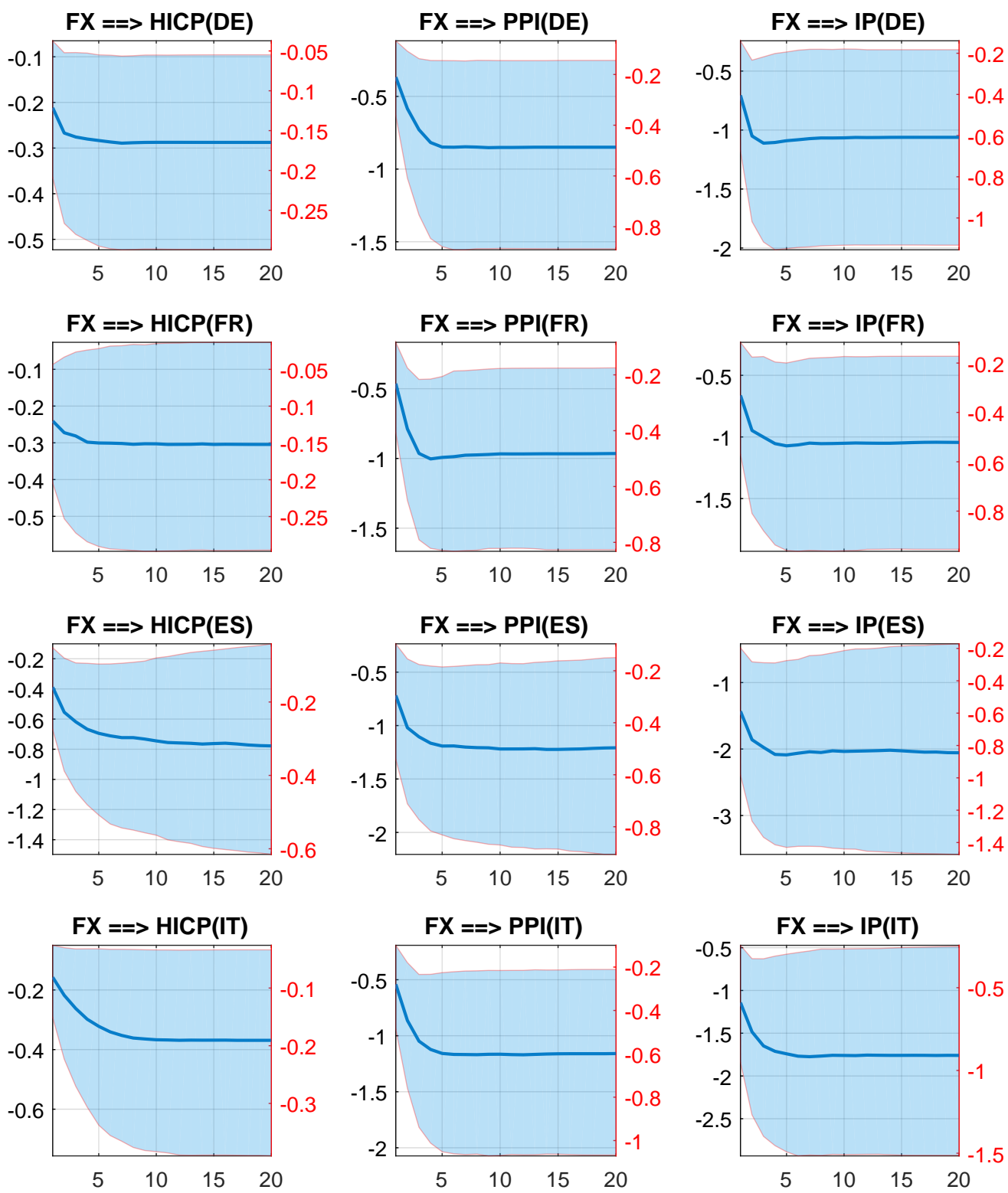

Figure 7: Baseline (left axis) and corrected (right axis) ERPT along the pricing chain at a country level (Germany, France, Spain and Italy). Impulse responses to one unit shock to exchange rate, median together with $68 \%$ interval. 

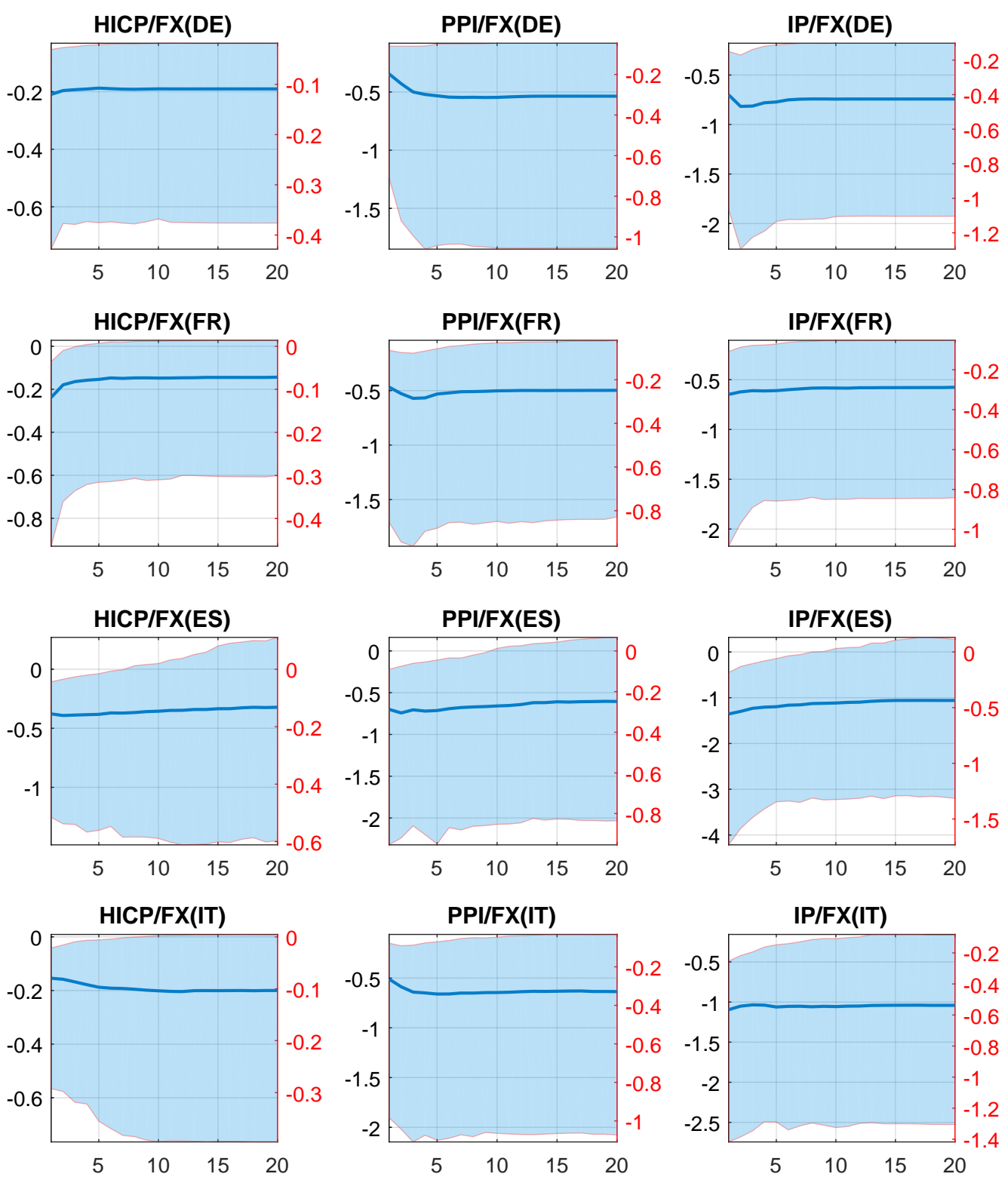

Figure 8: Baseline (left axis) and corrected (right axis) ERPT ratios along the pricing chain at a country level (Germany, France, Spain and Italy). Impulse responses to one unit shock to exchange rate, median together with $68 \%$ interval. 

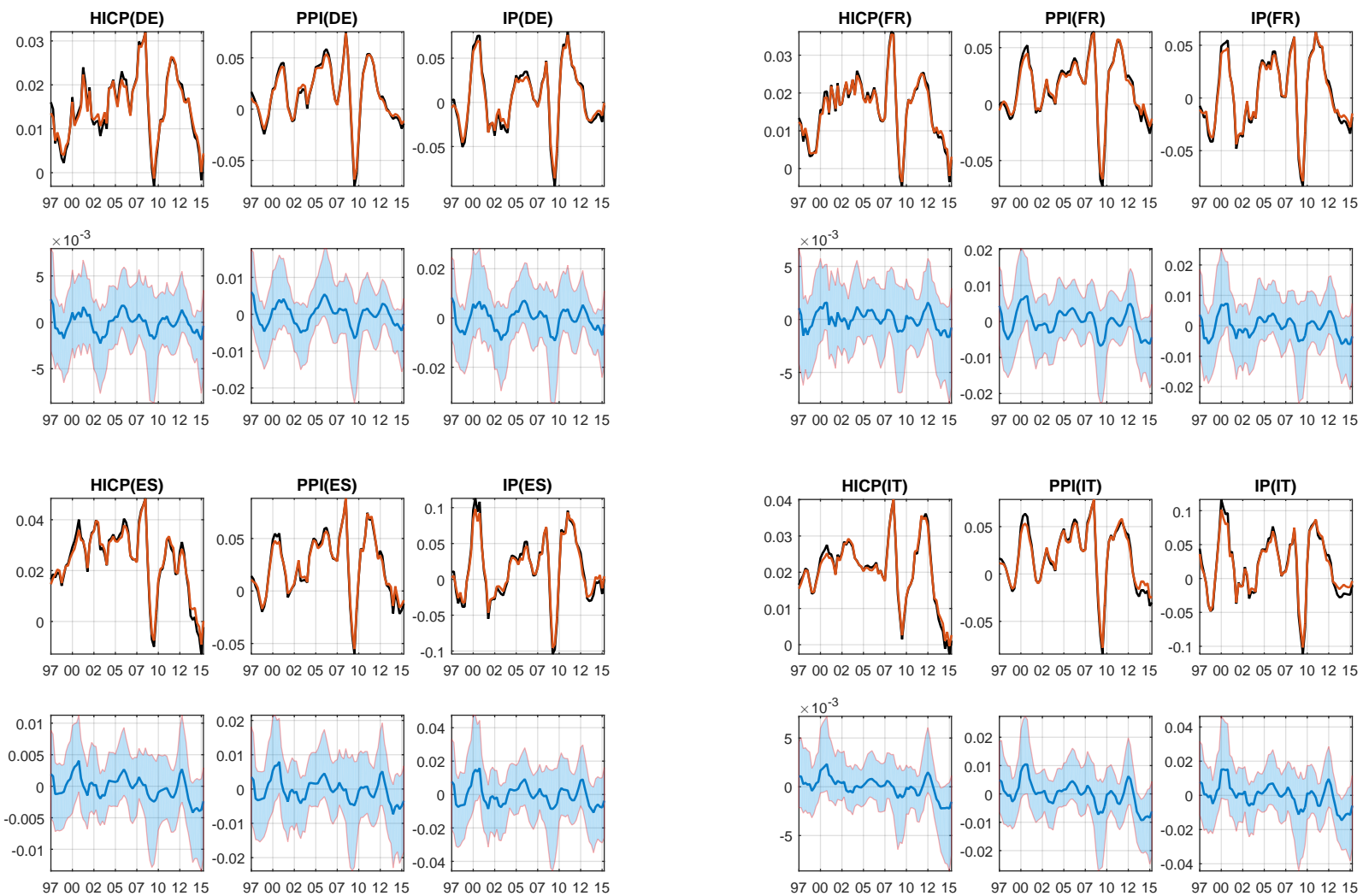

Figure 9: Inflation (in red) and counterfactual no exchange rate shock scenarios (in black) in the euro area at a country level 

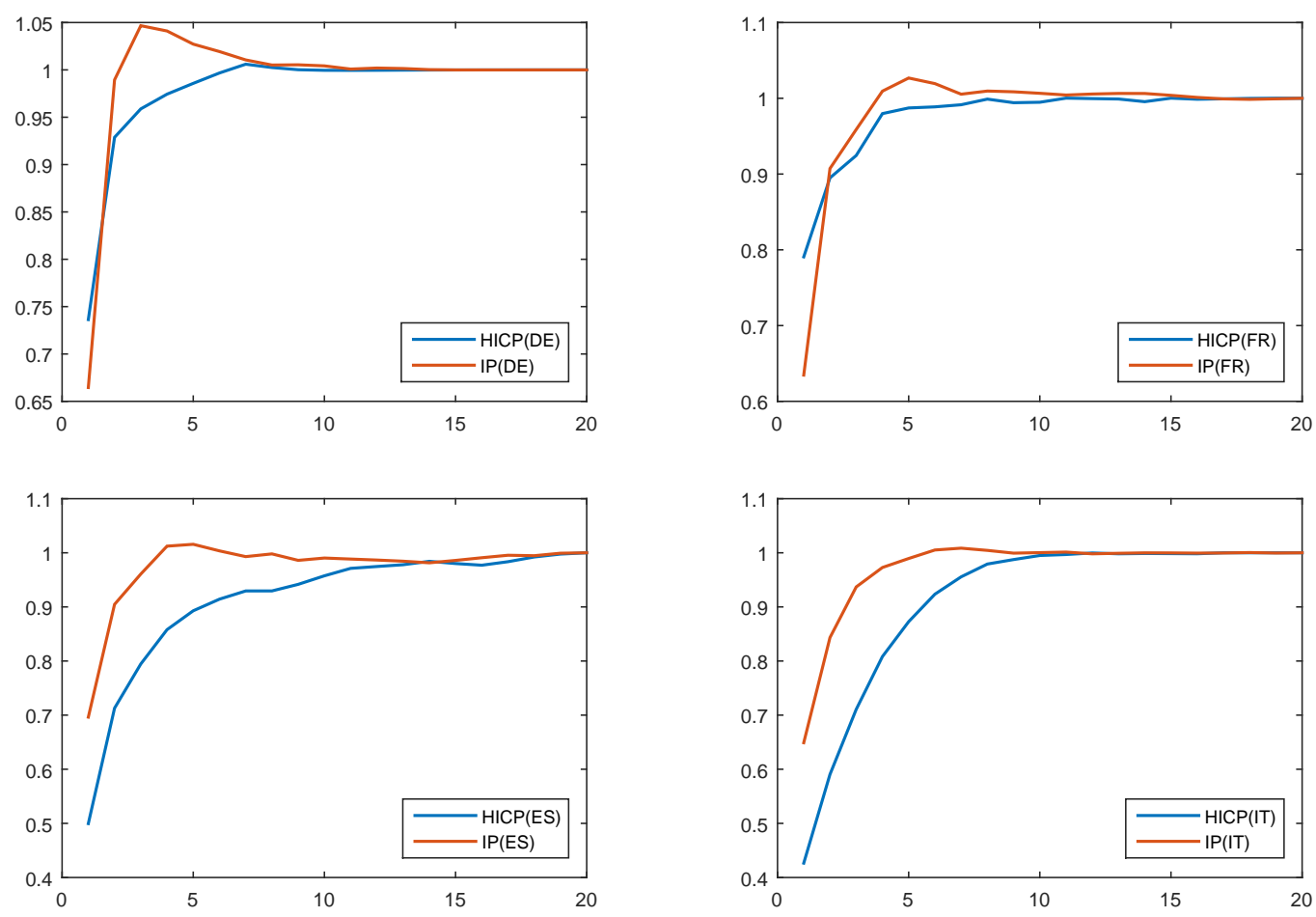

Figure 10: Speed of the pass-through for import prices and consumer prices in the euro area at country level
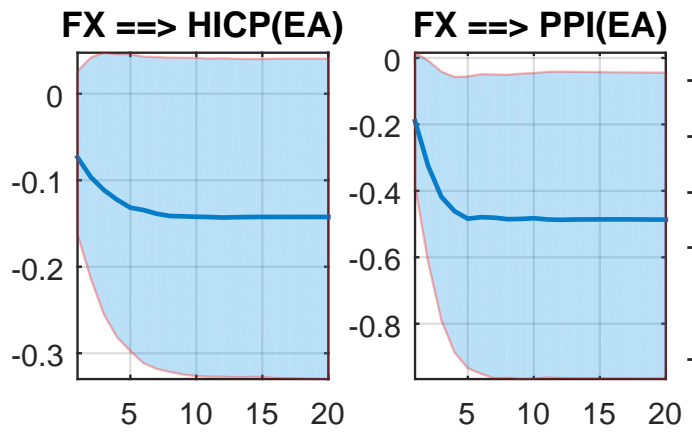

$F X==>I P(E A)$

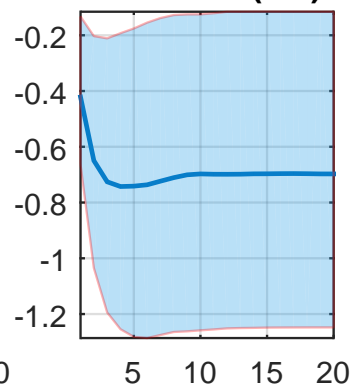

Figure 11: ERPT along the pricing chain in the euro area with relaxed identification pattern 

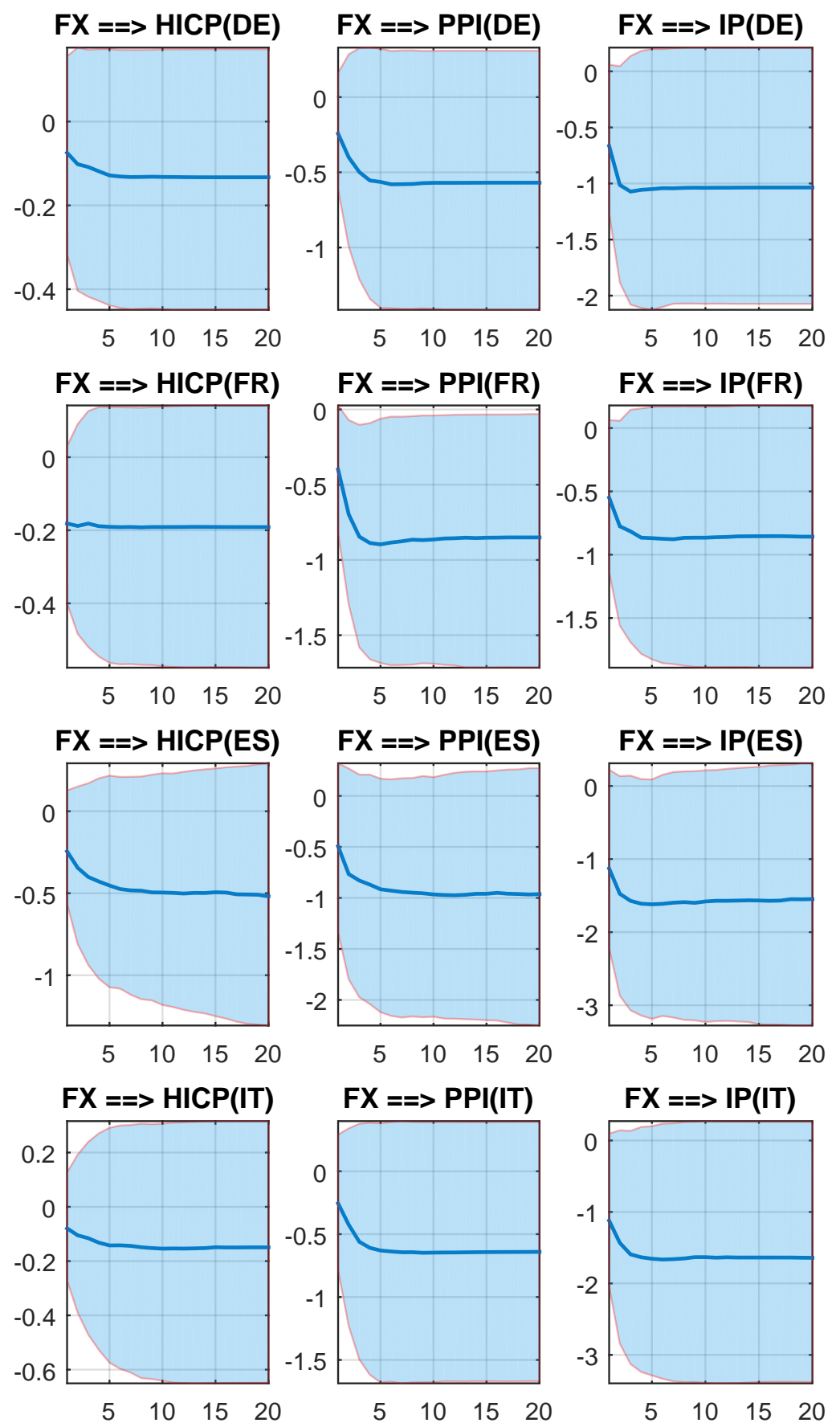

Figure 12: ERPT along the pricing chain in the euro area at country level with relaxed identification pattern 

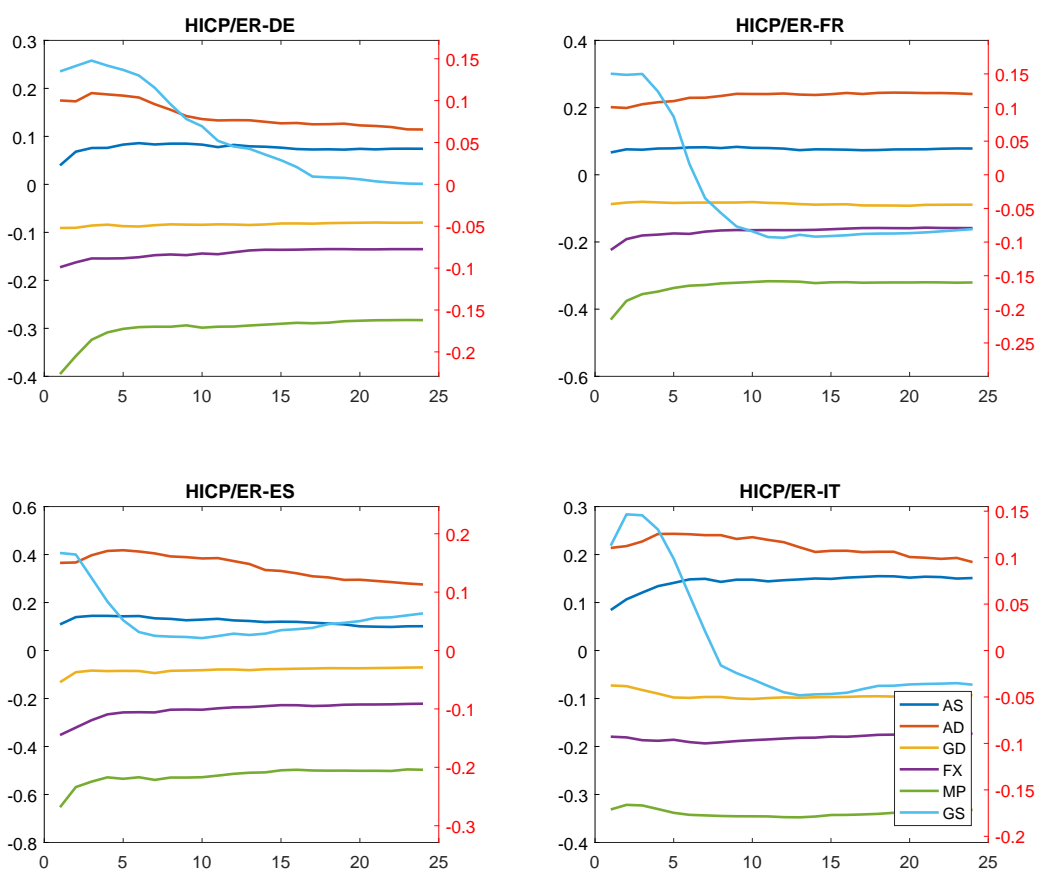

Figure 13: Baseline (left axis) and corrected (right axis) ERPT ratios for HICP, relative MP
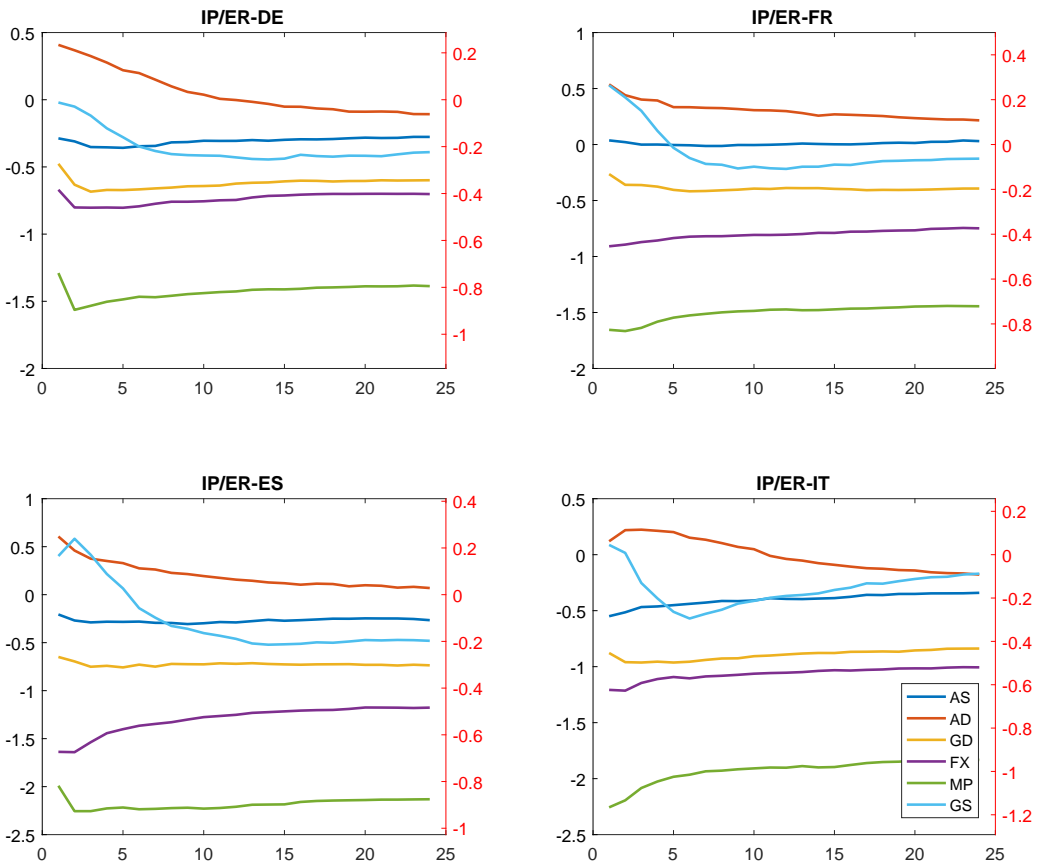

Figure 14: Baseline (left axis) and corrected (right axis) ERPT ratios for IP, relative MP 

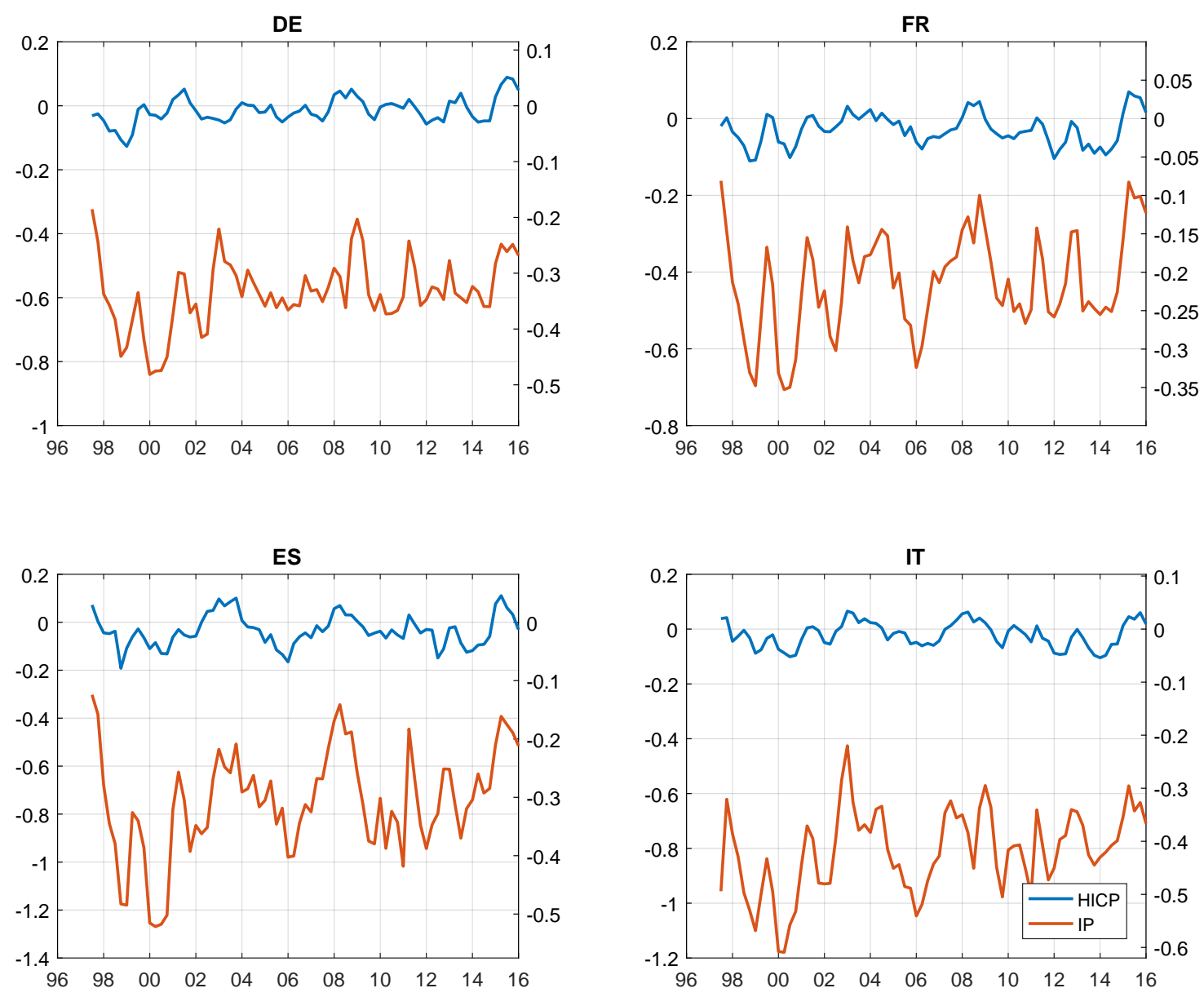

Figure 15: Baseline (left axis) and corrected (right axis) time varying ERPT at country level 

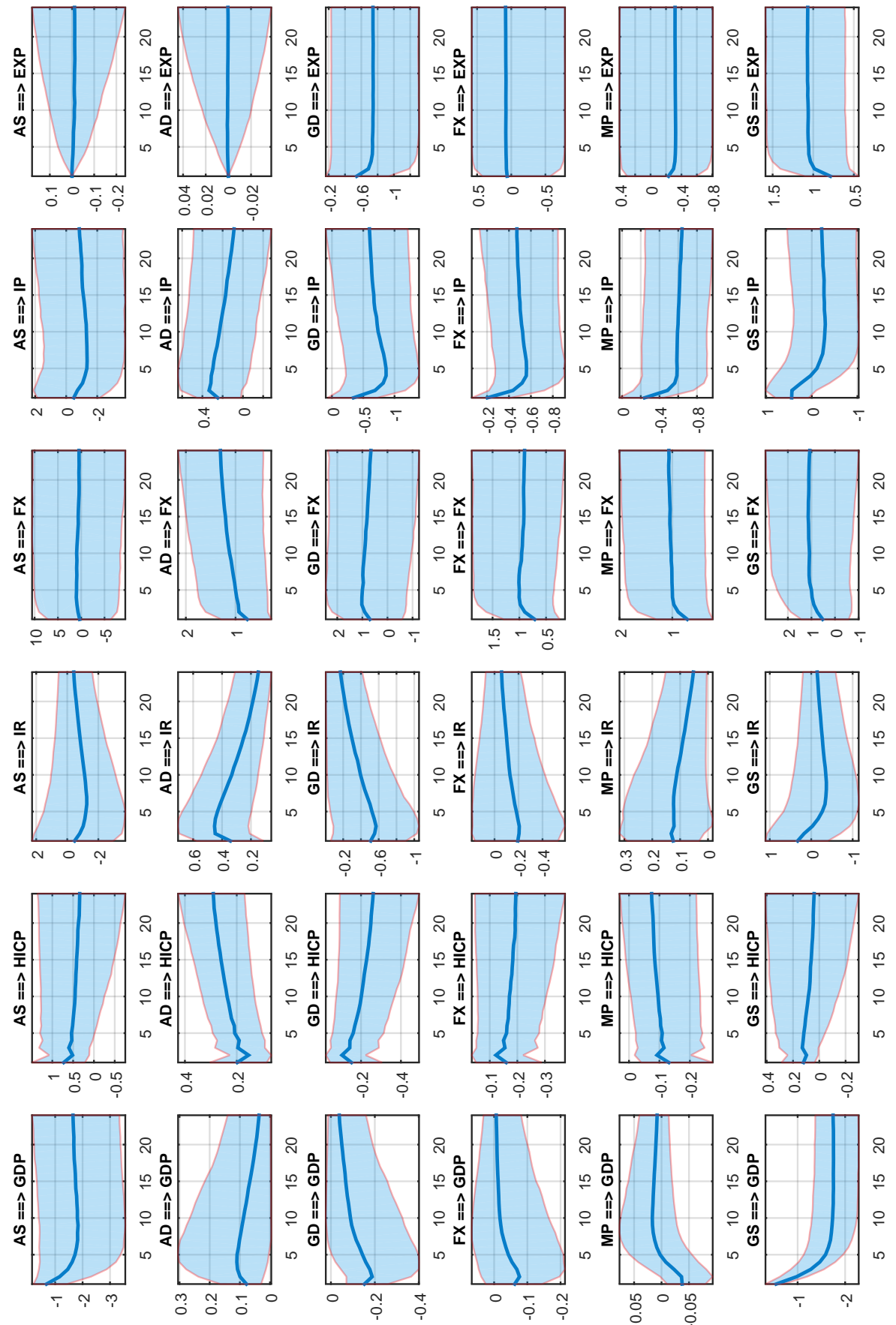

Figure 16: IRFs for EA, simple MP 

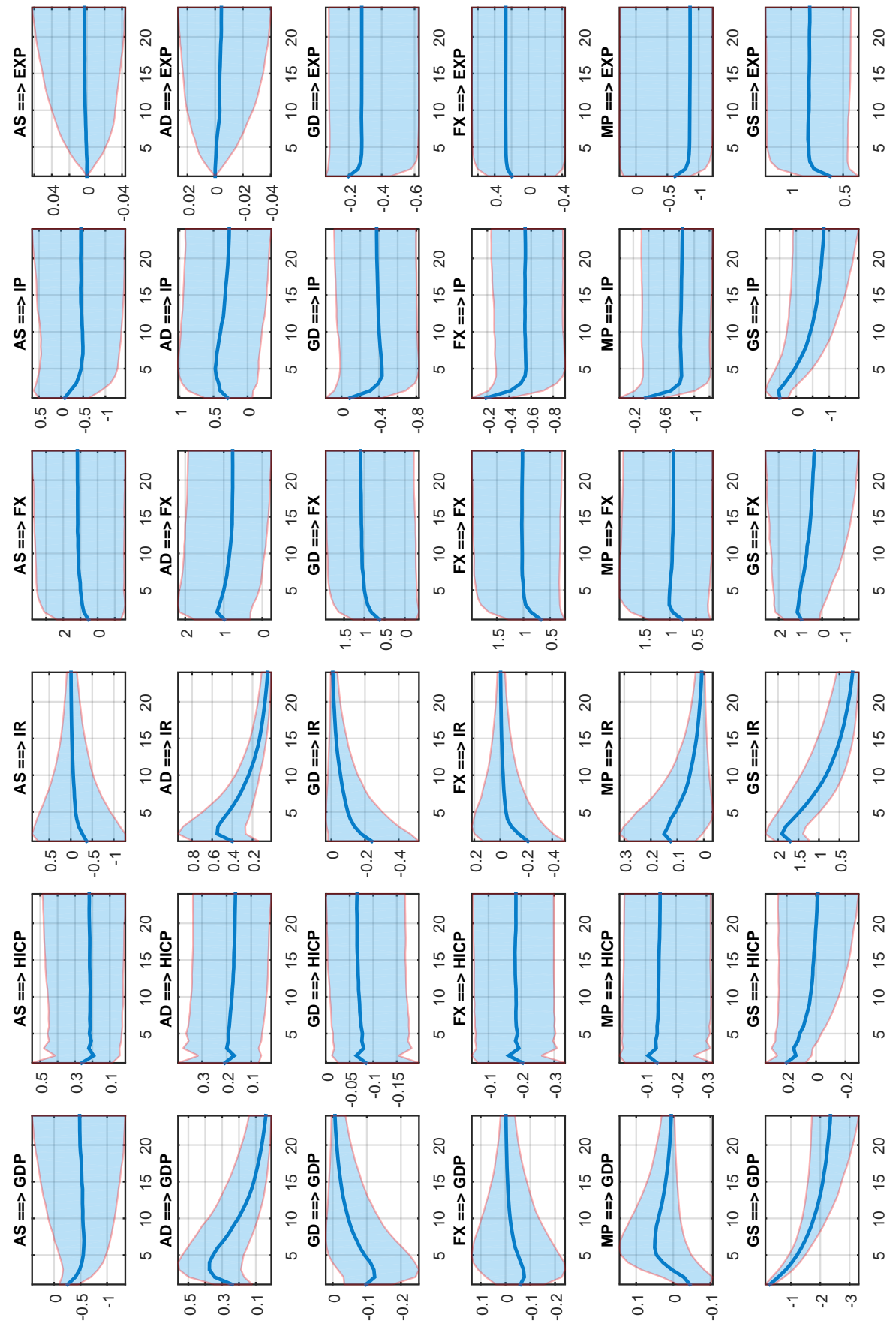

Figure 17: IRFs for EA, rel. MP 

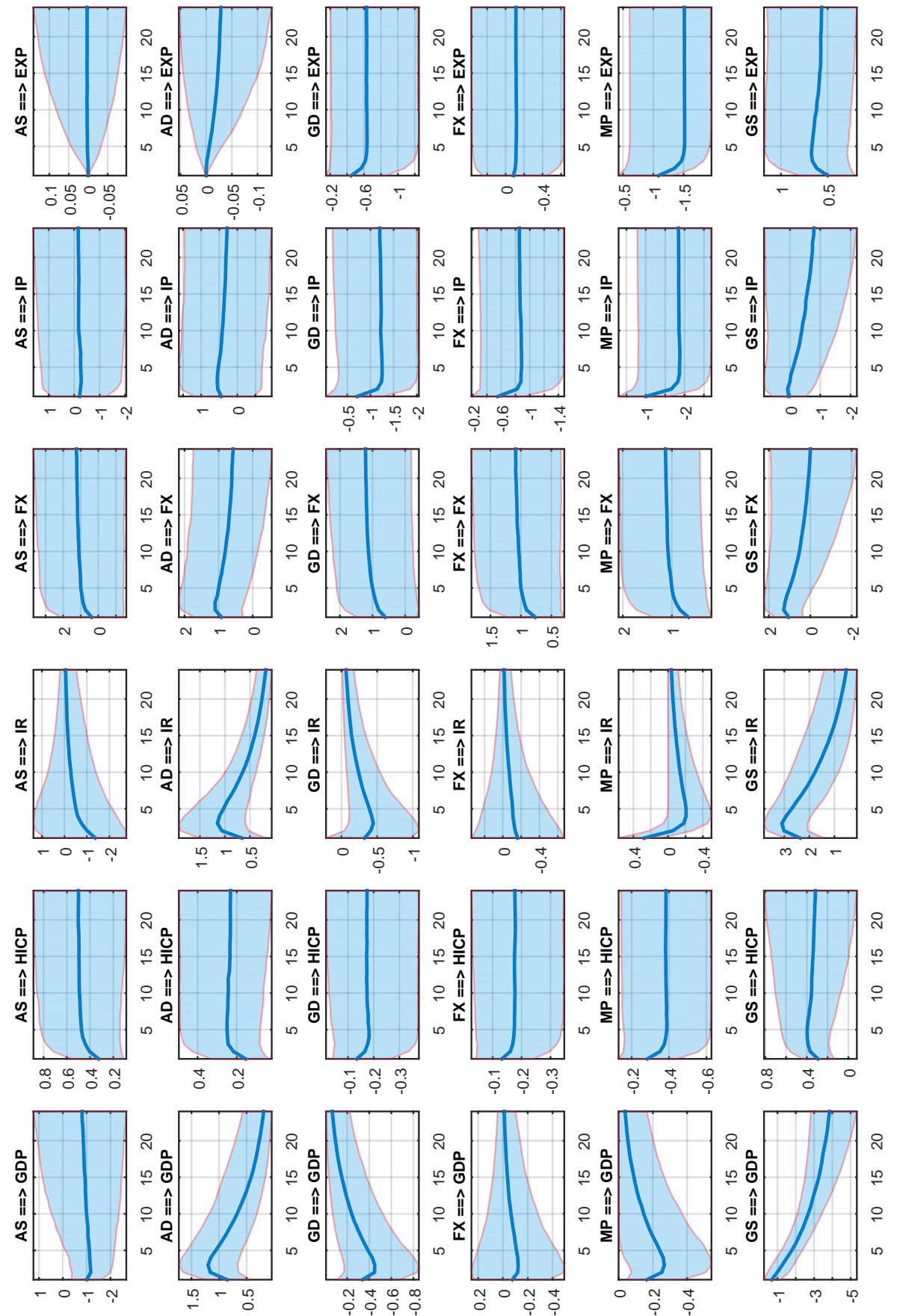

Figure 18: IRFs for DE, rel. MP 

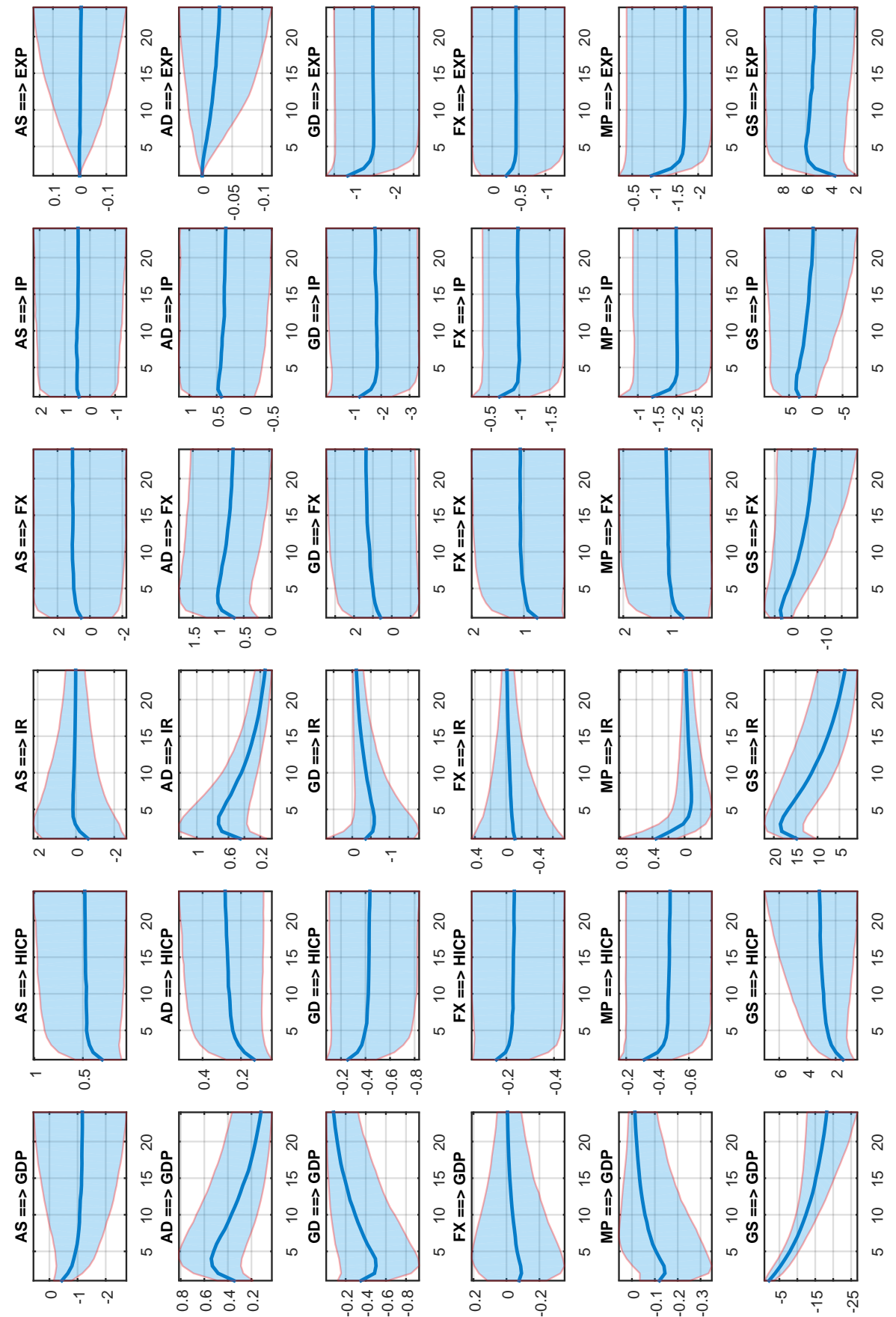

Figure 19: IRFs for FR, rel. MP 

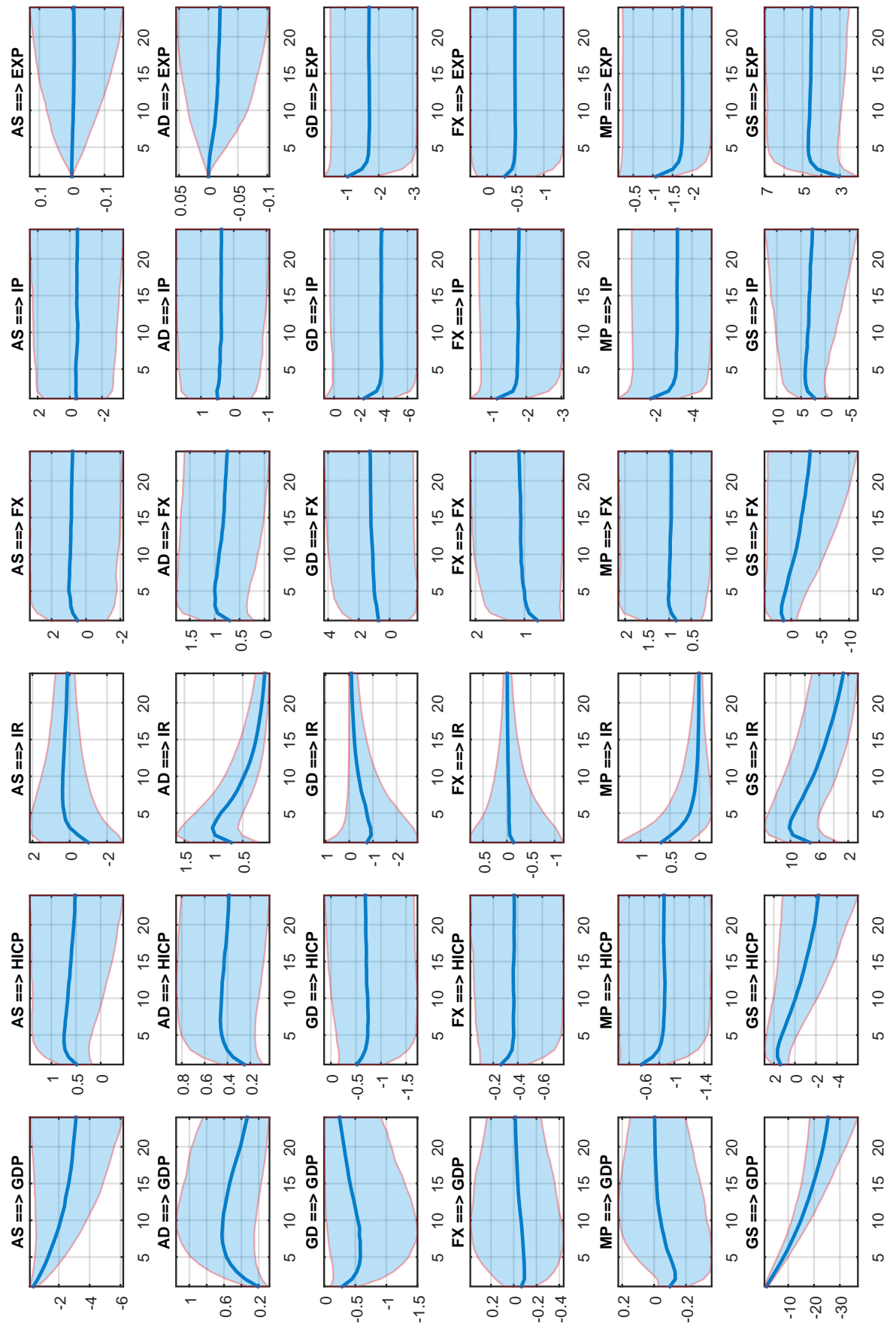

Figure 20: IRFs for ES, rel. MP 

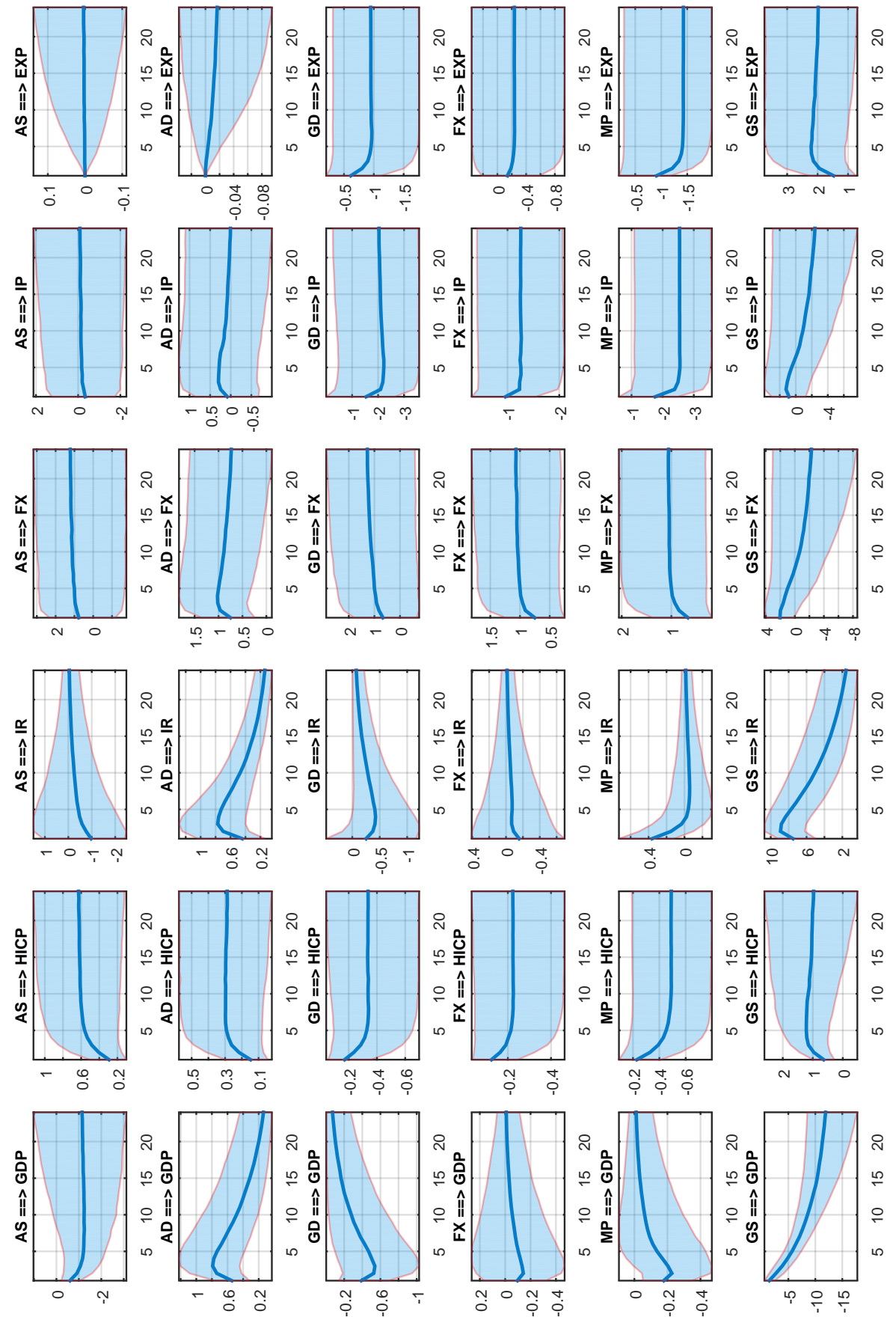

Figure 21: IRFs for IT, rel. MP 


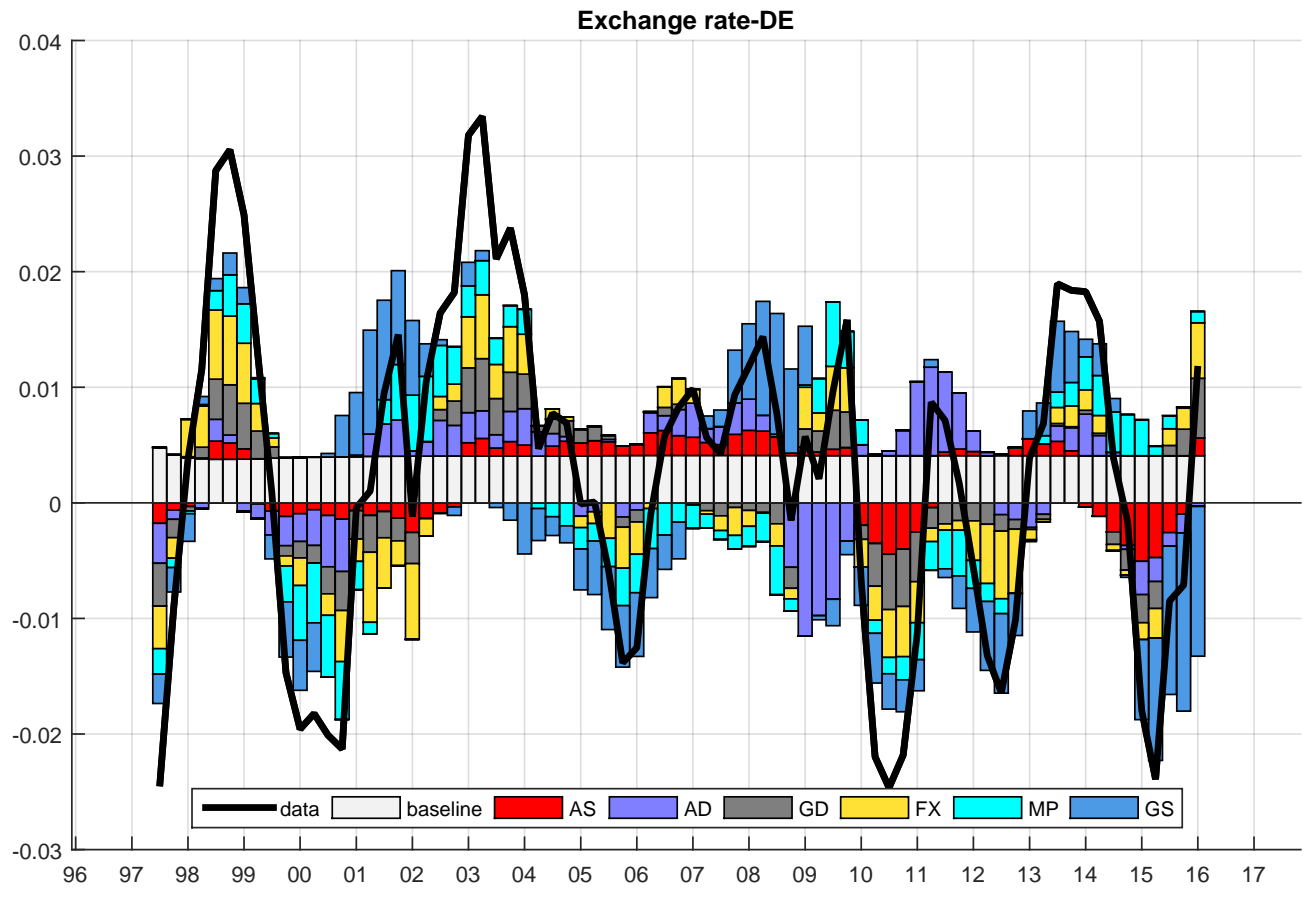

Figure 22: DE, historical decomposition, rel. MP

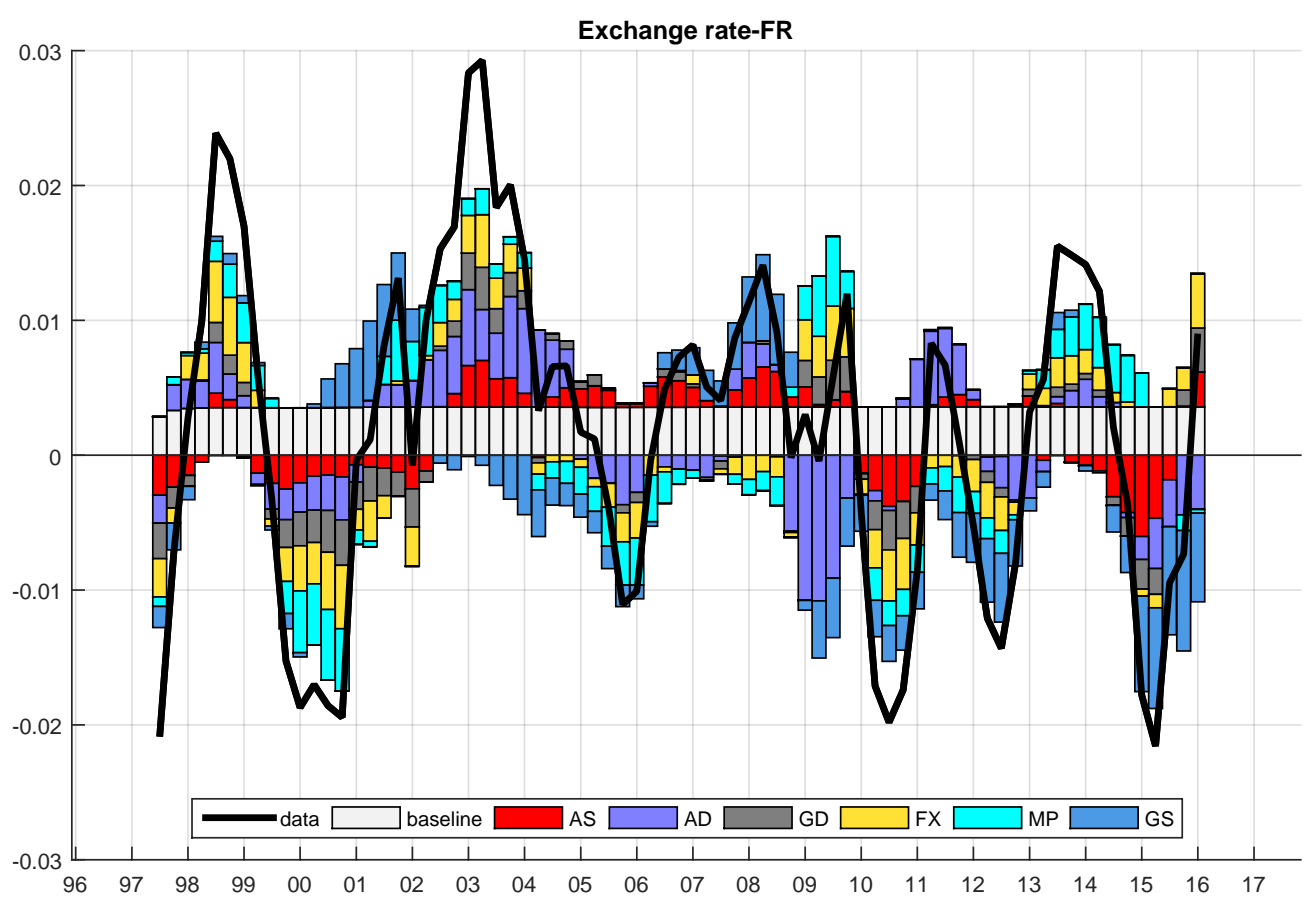

Figure 23: FR, historical decomposition, rel. MP 


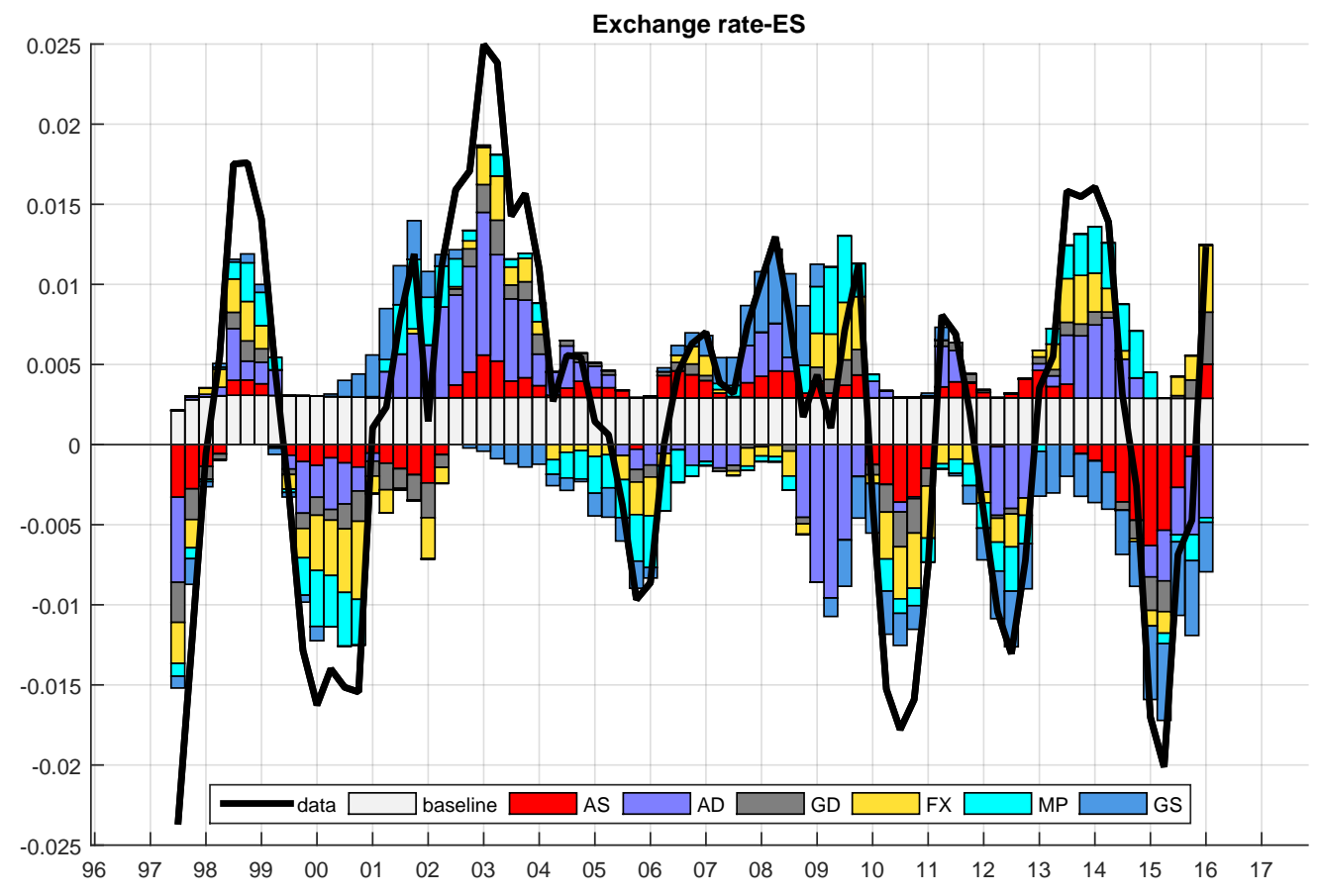

Figure 24: ES, historical decomposition, rel. MP

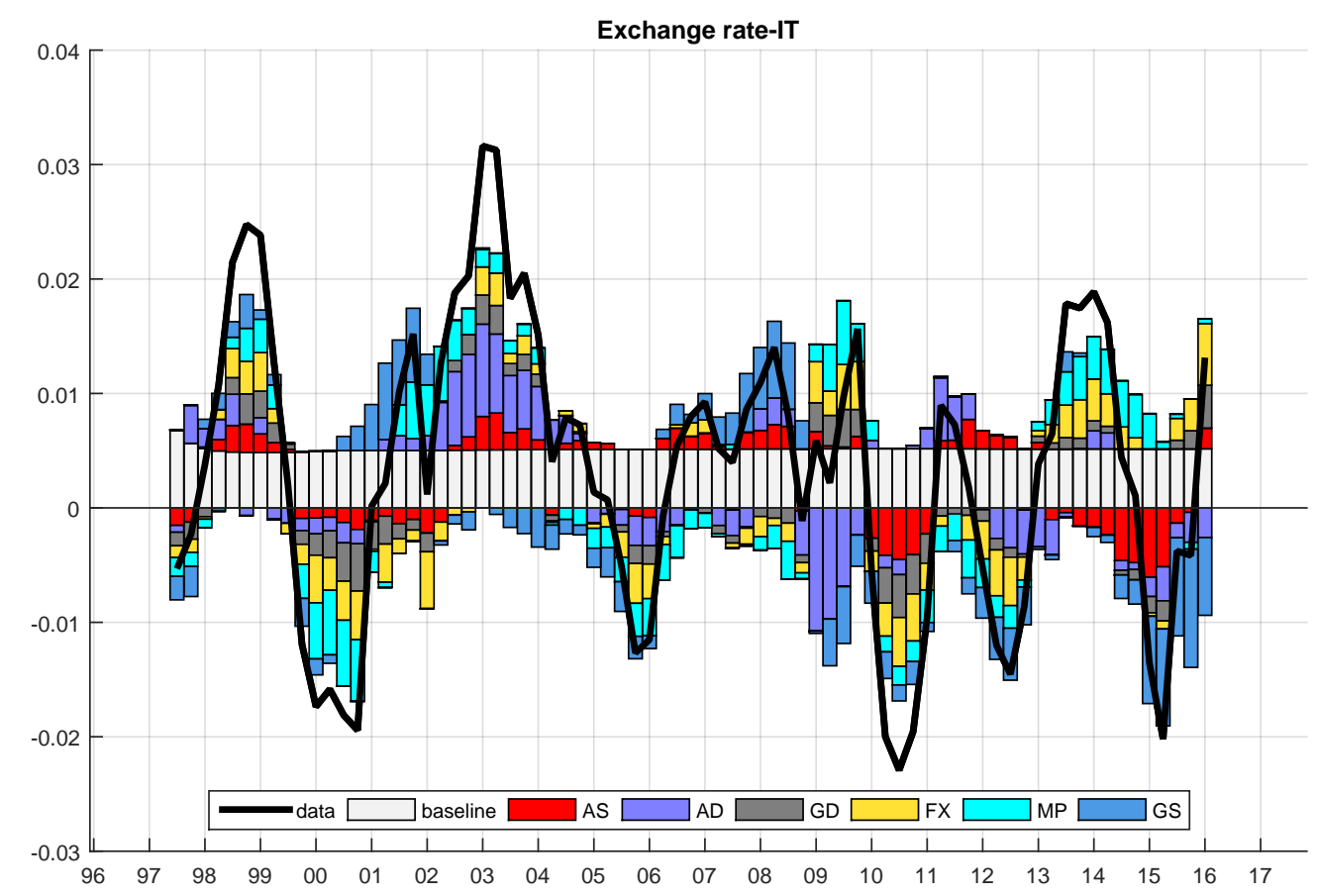

Figure 25: IT, historical decomposition, rel. MP 
Table 3: EA, HICP, rel. MP

\begin{tabular}{rrrrrrrr} 
Period & Percentile & AS & AD & GD & FX & MP & GS \\
\hline 1 & 50 & 0.04 & 0.21 & -0.06 & -0.28 & -0.17 & 0.16 \\
& 16 & -0.37 & 0.06 & -0.27 & -0.95 & -0.88 & 0.02 \\
& 84 & 0.37 & 0.88 & 0.12 & -0.08 & -0.04 & 0.46 \\
\hline 5 & 50 & 0.03 & 0.14 & -0.04 & -0.16 & -0.10 & 0.04 \\
& 16 & -0.21 & 0.00 & -0.18 & -0.51 & -0.46 & -0.15 \\
& 84 & 0.24 & 0.59 & 0.05 & -0.04 & 0.00 & 0.24 \\
\hline 13 & 50 & 0.03 & 0.10 & -0.04 & -0.15 & -0.10 & -0.02 \\
& 16 & -0.22 & -0.15 & -0.17 & -0.45 & -0.48 & -0.23 \\
& 84 & 0.22 & 0.52 & 0.05 & -0.03 & 0.00 & 0.18 \\
\hline
\end{tabular}

Table 4: EA, IP, rel MP

\begin{tabular}{rrrrrrrr} 
Period & Percentile & AS & AD & GD & FX & MP & GS \\
\hline 1 & 50 & 0.07 & 0.26 & 0.00 & -0.30 & -0.42 & 0.38 \\
& 16 & -0.44 & -0.07 & -0.52 & -1.08 & -1.34 & 0.07 \\
& 84 & 0.63 & 0.97 & 0.52 & -0.07 & -0.03 & 1.04 \\
\hline 5 & 50 & -0.15 & 0.27 & -0.25 & -0.49 & -0.68 & -0.09 \\
& 16 & -0.72 & -0.44 & -0.80 & -1.29 & -1.70 & -0.64 \\
& 84 & 0.52 & 1.64 & 0.31 & -0.23 & -0.27 & 0.49 \\
\hline \multirow{2}{*}{13} & 50 & -0.16 & 0.11 & -0.21 & -0.46 & -0.71 & -0.28 \\
& 16 & -0.74 & -0.79 & -0.76 & -1.21 & -1.82 & -1.13 \\
& 84 & 0.53 & 1.25 & 0.26 & -0.21 & -0.24 & 0.57 \\
\hline
\end{tabular}

Table 5: DE, HICP, rel. MP

\begin{tabular}{rrrrrrrr} 
Period & Percentile & AS & AD & GD & FX & MP & GS \\
\hline \multirow{2}{*}{1} & 50 & 0.04 & 0.17 & -0.09 & -0.17 & -0.40 & 0.24 \\
& 16 & -0.52 & 0.04 & -0.38 & -0.50 & -1.22 & 0.06 \\
& 84 & 0.46 & 0.79 & 0.20 & -0.05 & -0.16 & 0.60 \\
\hline 5 & 50 & 0.08 & 0.18 & -0.09 & -0.15 & -0.30 & 0.24 \\
& 16 & -0.41 & 0.01 & -0.37 & -0.53 & -0.80 & -0.19 \\
& 84 & 0.53 & 0.70 & 0.14 & -0.02 & -0.09 & 0.73 \\
\hline \multirow{2}{*}{13} & 50 & 0.08 & 0.13 & -0.08 & -0.14 & -0.29 & 0.07 \\
& 16 & -0.39 & -0.23 & -0.35 & -0.48 & -0.76 & -0.52 \\
& 84 & 0.52 & 0.70 & 0.12 & -0.01 & -0.09 & 0.60 \\
\hline
\end{tabular}

Table 6: DE, IP, rel. MP

\begin{tabular}{rrrrrrrr} 
Period & Percentile & AS & AD & GD & FX & MP & GS \\
\hline 1 & 50 & -0.29 & 0.41 & -0.48 & -0.67 & -1.29 & -0.02 \\
& 16 & -1.25 & -0.42 & -2.02 & -1.83 & -4.41 & -0.50 \\
& 84 & 0.74 & 2.71 & 0.71 & -0.28 & -0.37 & 0.78 \\
\hline 5 & 50 & -0.36 & 0.22 & -0.67 & -0.80 & -1.49 & -0.28 \\
& 16 & -1.34 & -1.16 & -2.01 & -2.00 & -3.81 & -1.11 \\
& 84 & 0.65 & 2.04 & 0.62 & -0.29 & -0.53 & 0.68 \\
\hline \multirow{2}{*}{13} & 50 & -0.30 & -0.02 & -0.62 & -0.73 & -1.41 & -0.44 \\
& 16 & -1.25 & -1.92 & -1.84 & -1.89 & -3.37 & -1.59 \\
& 84 & 0.74 & 1.72 & 0.35 & -0.24 & -0.57 & 0.82 \\
\hline
\end{tabular}


Table 7: FR, HICP, rel. MP

\begin{tabular}{rrrrrrrr} 
Period & Percentile & AS & AD & GD & FX & MP & GS \\
\hline 1 & 50 & 0.07 & 0.20 & -0.09 & -0.22 & -0.43 & 0.30 \\
& 16 & -0.38 & 0.05 & -0.44 & -0.77 & -1.36 & -0.13 \\
& 84 & 0.49 & 0.78 & 0.28 & -0.07 & -0.16 & 0.96 \\
\hline 5 & 50 & 0.08 & 0.22 & -0.08 & -0.17 & -0.34 & 0.17 \\
& 16 & -0.33 & 0.05 & -0.48 & -0.64 & -1.09 & -1.11 \\
& 84 & 0.50 & 0.63 & 0.32 & -0.01 & -0.05 & 1.04 \\
\hline 13 & 50 & 0.07 & 0.24 & -0.09 & -0.16 & -0.32 & -0.18 \\
& 16 & -0.37 & 0.02 & -0.50 & -0.63 & -1.09 & -0.88 \\
& 84 & 0.48 & 0.82 & 0.30 & 0.00 & -0.04 & 0.59 \\
\hline
\end{tabular}

Table 8: FR, IP, rel. MP

\begin{tabular}{rrrrrrrr} 
Period & Percentile & AS & AD & GD & FX & MP & GS \\
\hline 1 & 50 & 0.04 & 0.54 & -0.26 & -0.91 & -1.65 & 0.53 \\
& 16 & -1.38 & -0.25 & -2.29 & -3.13 & -5.48 & -0.53 \\
& 84 & 1.19 & 2.46 & 1.54 & -0.28 & -0.58 & 2.58 \\
\hline 5 & 50 & 0.00 & 0.33 & -0.41 & -0.84 & -1.55 & -0.03 \\
& 16 & -1.18 & -0.42 & -2.34 & -2.40 & -4.52 & -1.95 \\
& 84 & 1.19 & 1.62 & 1.21 & -0.22 & -0.38 & 1.77 \\
\hline 13 & 50 & 0.01 & 0.28 & -0.39 & -0.80 & -1.48 & -0.20 \\
& 16 & -1.07 & -0.79 & -2.12 & -2.27 & -4.21 & -1.50 \\
& 84 & 1.33 & 1.86 & 1.12 & -0.19 & -0.35 & 0.92 \\
\hline
\end{tabular}

Table 9: ES, HICP, rel. MP

\begin{tabular}{rrrrrrrr} 
Period & Percentile & AS & AD & GD & FX & MP & GS \\
\hline 1 & 50 & 0.11 & 0.37 & -0.13 & -0.35 & -0.65 & 0.41 \\
& 16 & -0.70 & 0.11 & -0.94 & -1.25 & -2.14 & -0.87 \\
& 84 & 0.71 & 1.40 & 0.51 & -0.11 & -0.25 & 1.52 \\
\hline 5 & 50 & 0.14 & 0.42 & -0.08 & -0.26 & -0.53 & 0.13 \\
& 16 & -0.51 & 0.09 & -0.82 & -0.99 & -2.15 & -0.84 \\
& 84 & 0.81 & 1.23 & 0.59 & 0.02 & -0.01 & 0.94 \\
\hline 13 & 50 & 0.12 & 0.36 & -0.08 & -0.24 & -0.51 & 0.06 \\
& 16 & -0.50 & -0.09 & -0.81 & -0.97 & -2.21 & -0.69 \\
& 84 & 0.81 & 1.32 & 0.60 & 0.10 & 0.15 & 0.84 \\
\hline
\end{tabular}

Table 10: ES, IP, rel. MP

\begin{tabular}{rrrrrrrr} 
Period & Percentile & AS & AD & GD & FX & MP & GS \\
\hline 1 & 50 & -0.21 & 0.61 & -0.65 & -1.64 & -1.99 & 0.40 \\
& 16 & -2.23 & -0.62 & -3.82 & -5.22 & -6.46 & -2.29 \\
& 84 & 1.80 & 3.52 & 2.75 & -0.50 & -0.10 & 3.13 \\
\hline 5 & 50 & -0.28 & 0.33 & -0.76 & -1.40 & -2.22 & 0.07 \\
& 16 & -1.83 & -0.88 & -3.73 & -4.28 & -6.81 & -3.31 \\
& 84 & 1.32 & 2.33 & 2.34 & -0.39 & 0.35 & 2.84 \\
\hline \multirow{2}{*}{13} & 50 & -0.28 & 0.15 & -0.71 & -1.23 & -2.19 & -0.51 \\
& 16 & -1.94 & -1.73 & -3.68 & -4.08 & -6.88 & -2.70 \\
& 84 & 1.45 & 2.50 & 2.29 & -0.23 & 0.62 & 1.80 \\
\hline
\end{tabular}


Table 11: IT, HICP, rel. MP

\begin{tabular}{rrrrrrrr} 
Period & Percentile & AS & AD & GD & FX & MP & GS \\
\hline \multirow{2}{1}{} & 50 & 0.08 & 0.21 & -0.07 & -0.18 & -0.33 & 0.22 \\
& 16 & -0.29 & 0.05 & -0.39 & -0.57 & -1.16 & 0.02 \\
& 84 & 0.44 & 0.78 & 0.23 & -0.05 & -0.11 & 0.61 \\
\hline 5 & 50 & 0.14 & 0.24 & -0.10 & -0.19 & -0.34 & 0.19 \\
& 16 & -0.35 & 0.04 & -0.59 & -0.63 & -1.07 & -0.95 \\
& 84 & 0.65 & 0.83 & 0.36 & -0.02 & -0.09 & 1.01 \\
\hline 13 & 50 & 0.15 & 0.22 & -0.10 & -0.18 & -0.35 & -0.09 \\
& 16 & -0.33 & -0.05 & -0.56 & -0.57 & -1.09 & -0.75 \\
& 84 & 0.69 & 0.90 & 0.29 & 0.01 & -0.08 & 0.64 \\
\hline
\end{tabular}

Table 12: IT, IP, rel. MP

\begin{tabular}{rrrrrrrr} 
Period & Percentile & AS & AD & GD & FX & MP & GS \\
\hline 1 & 50 & -0.55 & 0.12 & -0.88 & -1.21 & -2.26 & 0.09 \\
& 16 & -1.63 & -0.82 & -3.02 & -3.38 & -6.83 & -0.90 \\
& 84 & 0.48 & 2.10 & 1.33 & -0.46 & -0.76 & 1.41 \\
\hline 5 & 50 & -0.45 & 0.20 & -0.96 & -1.09 & -1.98 & -0.51 \\
& 16 & -1.42 & -0.66 & -3.07 & -2.75 & -4.89 & -2.04 \\
& 84 & 0.62 & 2.02 & 1.36 & -0.35 & -0.76 & 1.09 \\
\hline \multirow{2}{*}{13} & 50 & -0.40 & -0.05 & -0.88 & -1.05 & -1.89 & -0.36 \\
& 16 & -1.55 & -1.36 & -2.98 & -2.49 & -4.55 & -2.10 \\
& 84 & 0.77 & 1.65 & 1.13 & -0.30 & -0.70 & 1.33 \\
\hline
\end{tabular}
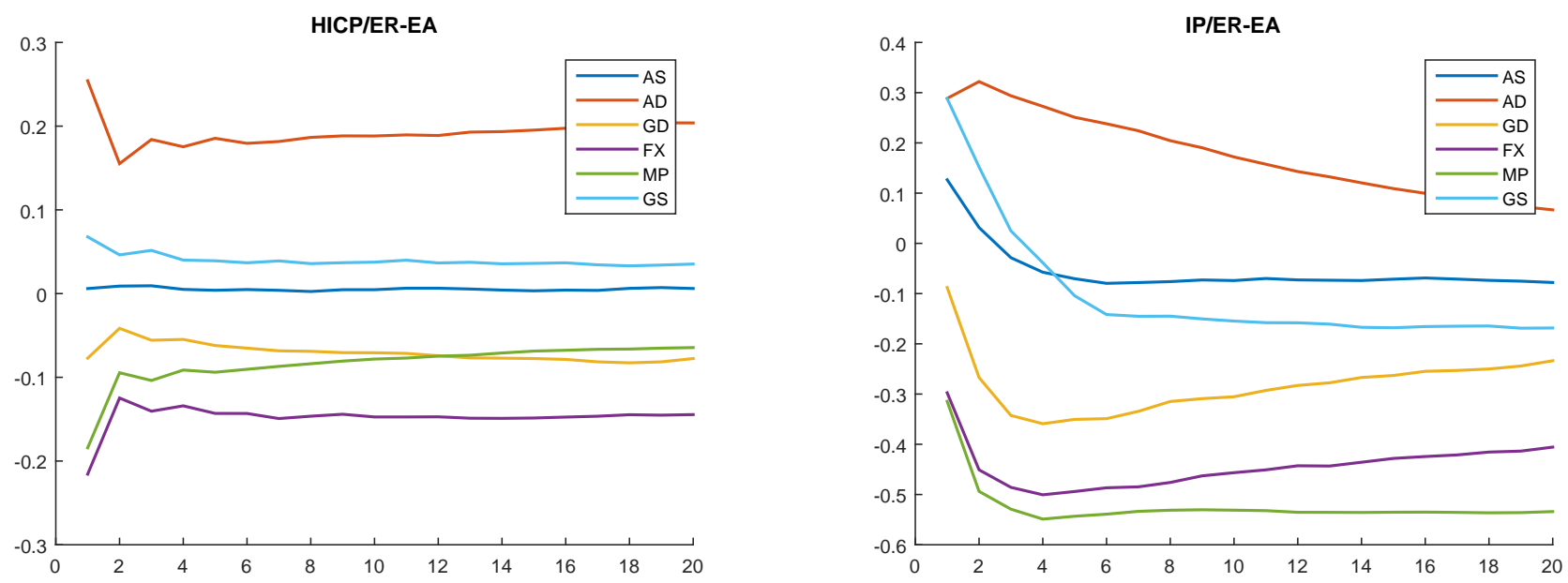

Figure 26: ERPT ratios for import deflator and HICP inflation in the euro area 


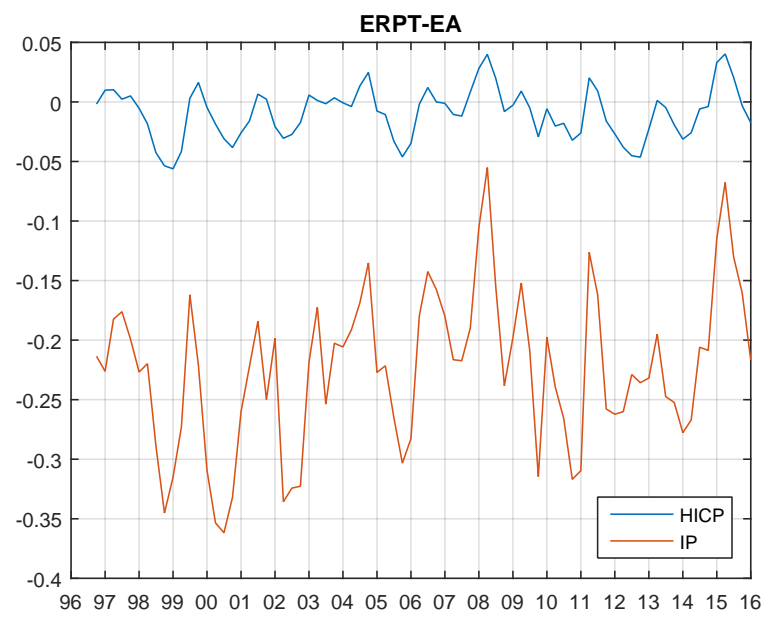

Figure 27: Shock dependent ERPT after one year in the euro area based on the six identified shocks (no rel. MP)

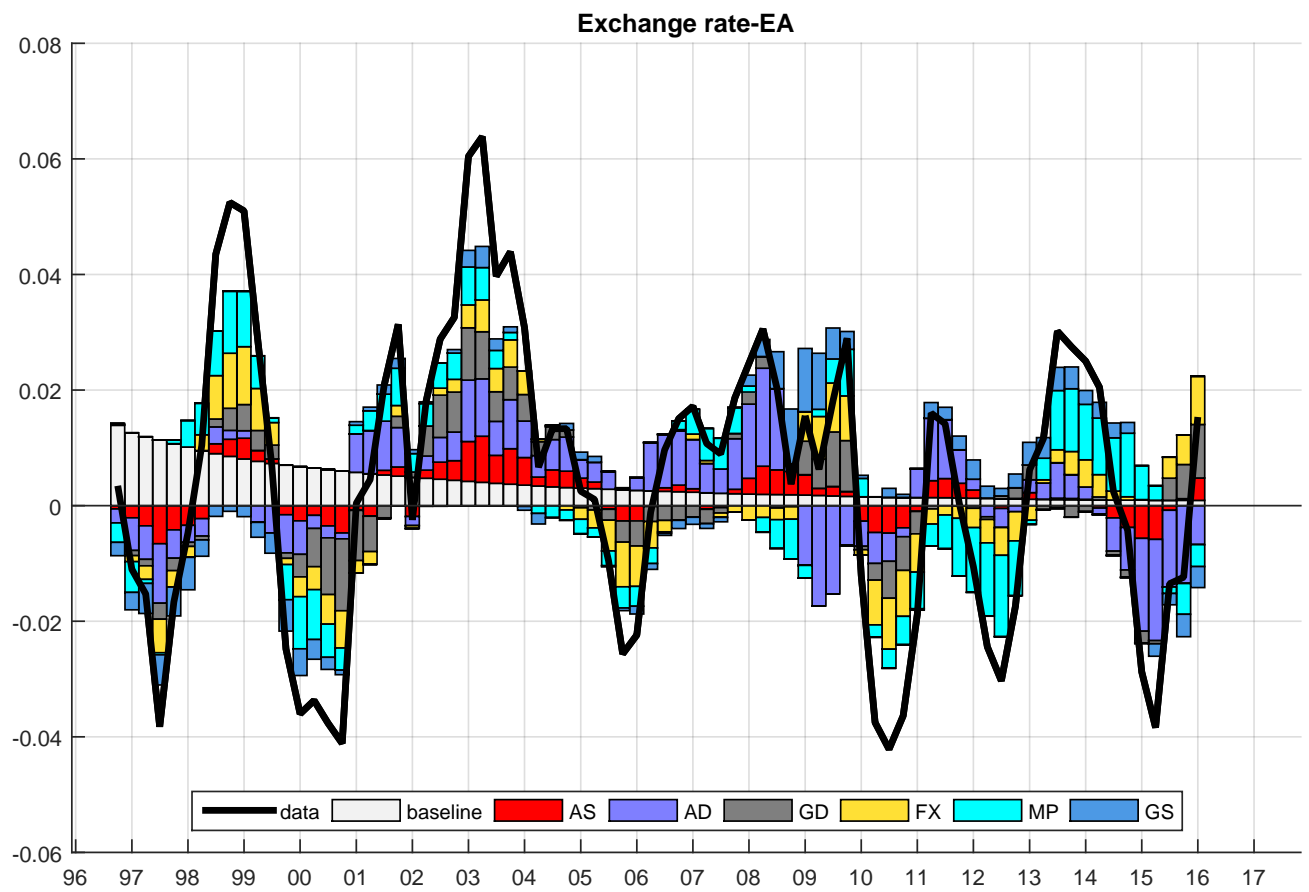

Figure 28: EA, historical decomposition 


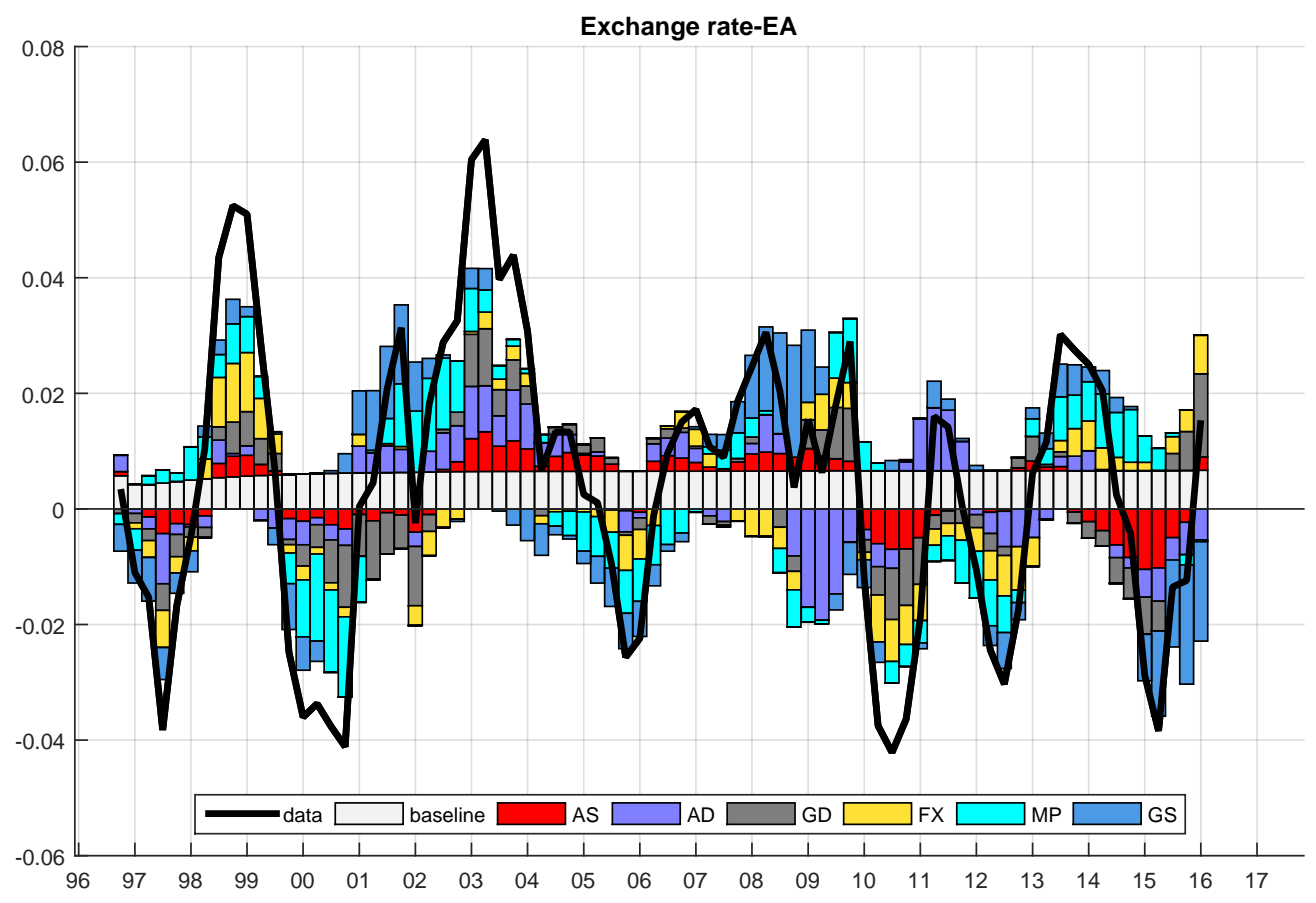

Figure 29: EA, historical decomposition, rel. MP 


